\title{
Interfacing Q-Chem and CHARMM to Perform QM/MM Reaction Path Calculations*
}

\author{
H. LEE WOODCOCK III, ${ }^{1}$ MILAN HODOŠC̆EK, ${ }^{2}$ ANDREW T. B. GILBERT, ${ }^{3}$ PETER M. W. GILL, ${ }^{3}$ \\ HENRY F. SCHAEFER III, ${ }^{4}$ BERNARD R. BROOKS ${ }^{1}$ \\ ${ }^{I}$ National Heart Lung and Blood Institute, National Institutes of Health, Bethesda, Maryland 20892 \\ ${ }^{2}$ Center for Molecular Modeling, National Institute of Chemistry, Hajdrihova 19, \\ SI-1000 Ljubljana, Slovenia \\ ${ }^{3}$ Research School of Chemistry, Australian National University, Canberra ACT 0200, Australia \\ ${ }^{4}$ Center for Computational Chemistry, University of Georgia, Athens, Georgia 30602-2556
}

Received 31 November 2005; Revised 21 April 2006; Accepted 6 May 2006

DOI 10.1002/jcc.20587

Published online 2 March 2007 in Wiley InterScience (www.interscience.wiley.com).

\begin{abstract}
A hybrid quantum mechanical/molecular mechanical (QM/MM) potential energy function with HartreeFock, density functional theory (DFT), and post-HF (RIMP2, MP2, CCSD) capability has been implemented in the CHARMM and Q-Chem software packages. In addition, we have modified CHARMM and Q-Chem to take advantage of the newly introduced replica path and the nudged elastic band methods, which are powerful techniques for studying reaction pathways in a highly parallel (i.e., parallel/parallel) fashion, with each pathway point being distributed to a different node of a large cluster. To test our implementation, a series of systems were studied and comparisons were made to both full QM calculations and previous QM/MM studies and experiments. For instance, the differences between $\mathrm{HF}$, DFT, MP2, and CCSD QM/MM calculations of $\mathrm{H} 2 \mathrm{O} \cdots \mathrm{H} 2 \mathrm{O}, \mathrm{H} 2 \mathrm{O} \cdots \mathrm{Na}^{+}$, and $\mathrm{H} 2 \mathrm{O} \cdots \mathrm{Cl}^{-}$complexes have been explored. Furthermore, the recently implemented polarizable Drude water model was used to make comparisons to the popular TIP3P and TIP4P water models for doing QM/MM calculations. We have also computed the energetic profile of the chorismate mutase catalyzed Claisen rearrangement at various QM/MM levels of theory and have compared the results with previous studies. Our best estimate for the activation energy is $8.20 \mathrm{kcal} / \mathrm{mol}$ and for the reaction energy is $-23.1 \mathrm{kcal} / \mathrm{mol}$, both calculated at the MP2/6-31+G(d)//MP2/6-31+G(d)/C22 level of theory.
\end{abstract}

(C) 2007 Wiley Periodicals, Inc. J Comput Chem 28: 1485-1502, 2007

Key words: QM/MM; CHARMM; Q-Chem; reaction path; chorismate mutase

\section{Introduction}

The study of condensed phase chemical and biochemical processes has been a major focus of computational and experimental chemists alike. In the past, molecular mechanics (MM) was the only feasible option available to computational chemists, as quantum mechanical (QM) methods typically scale as $\mathrm{N}^{3}$ or higher, where $\mathrm{N}$ is the number of basis functions. ${ }^{1}$ Recently, much effort has been put into reducing the scaling problems encountered with traditional QM methods. Great strides have been made in this endeavor via the development of fast multipole and linear scaling methods. ${ }^{2-6}$ In spite of these advances, application of QM methods to full biochemical systems is still prohibitively expensive.

In large part, this problem has been circumvented by the development of hybrid quantum mechanical/molecular mechanical methods (QM/MM). Warshel and Levitt ${ }^{7}$ first devised this scheme, with subsequent work by Singh and Kollman, ${ }^{8}$ and Field et al. ${ }^{9}$
Additionally, Car and Parrinello developed a unified scheme to perform molecular dynamics/density functional theory (CPMD) calculations. ${ }^{10}$ Another extremely popular QM/MM scheme developed by Morokuma and coworkers is dubbed the ONIOM method. This is a layered method in which different model chemistries are used in combination with an additivity scheme to arrive at a hybrid result. $^{11}$

The standard coupled QM/MM method involves division of the system of interest into three regions. The first region is treated with an appropriate QM level of theory, while the more economical, classical methods are applied to the larger second region of the system.

Correspondence to: H. Lee Woodcock III; e-mail: hlwood@nih.gov Contract/grant sponsor: NIH

Contract/grant sponsor: NSF; contract/grant number: CHE-0451445 
The third, and smallest area, is only needed when truncation of a region necessitates the cutting of a bond and, therefore, the creation of an interface region separating the QM and MM sections. ${ }^{9,12-16}$ Atoms that are believed to be most significant (i.e., directly participating in the chemical process of interest) are logical choices for inclusion in the QM region, while less critical parts of the system may be treated via classical methods. Electrostatic and van der Waals interactions between QM and MM atoms are included through a coupled potential.

Numerous groups have reported the implementation of hybrid QM/MM schemes. ${ }^{9-26}$ Typically, these have employed semiempirical (AM1,PM3) ${ }^{27,28}$ or empirical valence bond (EVB) methods ${ }^{29}$ to describe the quantum mechanical Hamiltonian. Recently, there has been a greater emphasis placed upon using $a b$ initio $^{30}$ or density functional theory (DFT) ${ }^{31}$ to account for the quantum interactions. ${ }^{32-35}$ Although semiempirical methods are much faster and have been used effectively, the weaknesses of these methods have also been well documented. ${ }^{9,17,36,37}$ The logical step to overcome the accuracy and applicability limitations of semiempirical theories has been to transition into using more rigorous quantum mechanical methods.

In our current work, we report the extension of CHARMM's QM/MM capabilities to utilize Q-Chem's efficient ab initio, DFT, and post-HF methods (RIMP2, MP2, CCSD). ${ }^{38,39}$ In addition to standard QM/MM functionality, which has become a hallmark for studying important topics such as solvation, ${ }^{40,41}$ spectroscopy, ${ }^{42,43}$ and conformational properties, ${ }^{44}$ there has been a growing interest in developing and implementing parallel reaction path methods. ${ }^{45-47}$ Hence, our current Q-Chem interface fully supports CHARMM's parallel/parallel replica path method (RPM) ${ }^{46}$ and nudged elastic band (NEB) method ${ }^{47-50}$ and is, in part, based on the previous implementations of Gamess-US ${ }^{51}$ and Gamess-UK. ${ }^{52}$ However, unlike the Gamess QM/MM interfaces, the Q-Chem interface is completely independent of CHARMM and is therefore far easier to setup and employ.

Our CHARMM/Q-Chem interface has been designed in a general fashion to support most constraints and restraints implemented in CHARMM in addition to the major force fields incorporated into CHARMM (CHARMM, AMBER, CFF, MMFF, etc.). CHARMM's major molecular dynamics capabilities are fully supported via QM/MM with Q-Chem (i.e., MD, LD, SGLD). Very recently we have added support for CHARMM's linear free energy perturbation (FEP) routines. This not only involves support for the BLOCK routines in CHARMM, which allow for energetic analysis and FEP simulations ${ }^{53}$ but also support for the PERT functionality. Until now FEP calculations in CHARMM have only had the capacity to run with semiempirical QM/MM methods, ${ }^{54}$ however, the Q-Chem QM/MM interface now fully supports ab initio FEP (PERT) calculations. Details of this will be presented in a future publication. Possible future developments of the current interface include but are not limited to Gaussian blurred MM charge gradients, QM/MM Hessians, and support for excited state QM regions.

In the following sections, we briefly review the theoretical basis on which hybrid QM/MM methodology is based and we describe the implementation of the Q-Chem/CHARMM interface that controls standard QM/MM calculations as well as parallel/parallel reaction pathway calculations. In addition, we evaluate a series of test cases to validate our implementation.

\section{Computational Methodology}

The hybrid QM/MM methodology employed in this work is based largely on the work of Lyne et al. ${ }^{17}$ and Field et al. ${ }^{9}$ which have described both semiempirical and $a b$ initio/DFT QM/MM implementations. The fundamental principle which allows for this description is the definition and partitioning of an effective Hamiltonian $\left(\hat{H}_{\text {eff }}\right)$.

$$
\hat{H}_{\mathrm{eff}}=\hat{H}_{\mathrm{QM}}+\hat{H}_{\mathrm{MM}}+\hat{H}_{\mathrm{QM} / \mathrm{MM}}
$$

where $\hat{H}_{\mathrm{QM}}$ is the pure QM Hamiltonian, $\hat{H}_{\mathrm{MM}}$ is the classical Hamiltonian, and $\hat{H}_{\mathrm{QM} / \mathrm{MM}}$ is the hybrid QM/MM Hamiltonian.

$$
\hat{H}_{\mathrm{QM} / \mathrm{MM}}=-\sum_{\mathrm{i}, \mathrm{M}} \frac{q_{\mathrm{m}}}{r_{\mathrm{im}}}+\sum_{\mathrm{A}, \mathrm{M}} \frac{Z_{\mathrm{A}} q_{\mathrm{m}}}{R_{\mathrm{AM}}}+\sum_{\mathrm{A}, \mathrm{M}}\left(\frac{A_{\mathrm{AM}}}{R_{\mathrm{AM}}^{12}}-\frac{B_{\mathrm{AM}}}{R_{\mathrm{AM}}^{6}}\right)
$$

where the first term in eq. (2) accounts for the interaction of QM electrons with external point charges and is incorporated in the wave function via the addition of one electron integrals to the Fock matrix. The second term describes the interaction of QM Nuclei with external point charges, while the third term defines the Lennard-Jones interaction energy and is needed to account for Pauli repulsion between $\mathrm{QM}$ atoms and external point charges. Using these definitions, one can now construct an effective Schrödinger equation

$$
\hat{H}_{\text {eff }} \Psi\left(r, R_{\alpha}, R_{\mathrm{M}}\right)=E_{\mathrm{rxn}} \Psi\left(r, R_{\alpha}, R_{\mathrm{M}}\right)
$$

where $\Psi$, the QM wave function, is a function of $r$ (electron coordinates), $R_{\alpha}$ (QM Nuclei), and $R_{\mathrm{M}}$ (MM Nuclei). Using eqs. (1) and (2), the total energy is defined as

$$
\begin{aligned}
E_{\mathrm{rxn}}\left(r, R_{\alpha}, R_{\mathrm{M}}\right) & =\frac{\left\langle\Psi\left|\hat{H}_{\mathrm{QM}}\right| \Psi\right\rangle+\left\langle\Psi\left|\hat{H}_{\mathrm{QM} / \mathrm{MM}}\right| \Psi\right\rangle}{\langle\Psi \mid \Psi\rangle}+E_{\mathrm{MM}} \\
& =E_{\mathrm{QM}}+E_{\mathrm{QM} / \mathrm{MM}}+E_{\mathrm{MM}}
\end{aligned}
$$

Given the current formulation of the hybrid QM/MM coupling scheme, the external point charges do not experience polarization from the QM region. However, polarization can be included by coupling the induced dipole moments from external charges to the effective Hamiltonian [eq. (1)] via the following formula ${ }^{55,56}$

$$
\hat{H}_{\mathrm{Pol}}=-\frac{1}{2} \sum_{\mathrm{M}} \sum_{\mathrm{A}} \frac{\mu_{\mathrm{M}}^{\mathrm{ind}}}{r_{\mathrm{AM}}^{3}} \mathbf{r}_{\mathrm{AM}}+\frac{1}{2} \sum_{\mathrm{M}} \sum_{\mathrm{A}} \frac{Z_{\mathrm{M}} \mu_{\mathrm{M}}^{\mathrm{ind}}}{R_{\mathrm{AM}}^{3}} \mathbf{R}_{\mathrm{MA}}
$$

where $\mu_{\mathrm{M}}^{\text {ind }}$ is the induced dipole moment on external point charge $M$. The addition of this term to the effective Hamiltonian, in a selfconsistent fashion, requires large amounts of computational time. ${ }^{17}$ However, the self-consistent optimization may be coupled with the convergence of the wavefunction, providing this capability without increasing the number of SCF iterations. On the other hand, 
Table 1. Ab Initio Results for the Water Dimer.

\begin{tabular}{llcccc}
\hline Method & \multicolumn{1}{c}{ Basis set } & $\Delta E$ & $d(\mathrm{H} \cdots \mathrm{O})$ & \multicolumn{1}{c}{ O $\cdots \mathrm{HO}$} & $d(\mathrm{O} \cdots \mathrm{O})$ \\
\hline HF & cc-pVTZ & 4.432 & 2.085 & 170.4 & 3.020 \\
HF & cc-pVQZ & 4.020 & 2.089 & 176.7 & 3.031 \\
HF & aug-cc-pVTZ & 3.755 & 2.096 & 175.5 & 3.040 \\
HF & aug-cc-pVQZ & 3.741 & 2.094 & 175.8 & 3.036 \\
B3LYP & cc-pVTZ & 6.303 & 1.940 & 171.6 & 2.903 \\
B3LYP & cc-pVQZ & 5.285 & 1.954 & 171.2 & 2.914 \\
B3LYP & aug-cc-pVTZ & 4.732 & 1.960 & 169.8 & 2.920 \\
B3LYP & aug-cc-pVQZ & 4.608 & 1.966 & 171.3 & 2.927 \\
MP2 & cc-pVTZ & 6.079 & 1.948 & 170.2 & 2.904 \\
MP2 & cc-pVQZ & 5.285 & 1.944 & 169.7 & 2.899 \\
MP2 & aug-cc-pVTZ & 5.219 & 1.950 & 170.1 & 2.909 \\
MP2 & aug-cc-pVQZ & 5.136 & 1.948 & 170.0 & 2.902 \\
LDA $^{17}$ & 6-31G* & 10.74 & 1.986 & 171.3 & 2.898 \\
BLYP & 6-31G* & 6.32 & 1.921 & 174.1 & 2.882 \\
B3LYP & 6-31G* & 7.87 & 1.91 & 164.3 & 2.86 \\
Extrapolated $^{74}$ & & $5.02 \pm 0.05$ & & & 2.91 \\
Focal point & & $5.02 \pm 0.07$ & & & 2.91 \\
Experimental $^{76,77}$ & & $5.44 \pm 0.7$ & & & 2.98 \\
\hline
\end{tabular}

Binding energies, $\Delta E$, are reported in $\mathrm{kcal} / \mathrm{mol}$. Geometric parameters are reported in angstroms (bond distances) and degrees (bond angles).

incorporating polarization in this manner would limit some SCF optimization schemes (i.e., dynamic integral thresholds) and would likely increase the total cost by at least a factor of two. New force fields are being developed that do allow the QM wave function

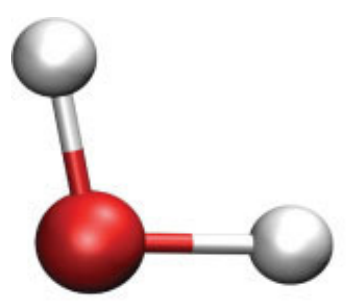

QM: H-Bond Donor

(a)

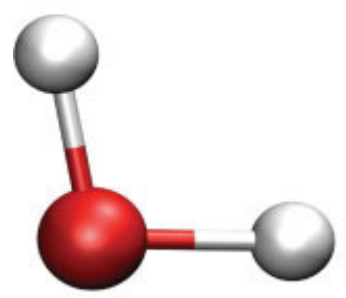

MM: H-Bond Donor
MM: H-Bond Acceptor

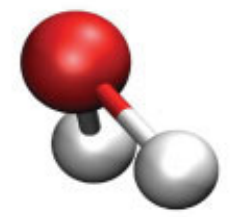

QM: H-Bond Acceptor

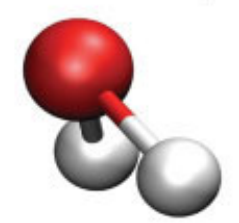

(b)

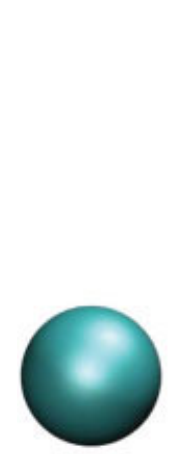

(a)
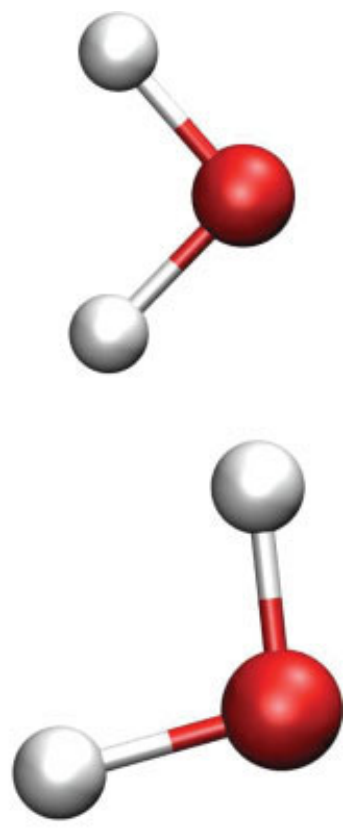

(b)

Figure 2. Water $\cdots \mathrm{Cl}^{-}$complex; (a) incorrect $\mathrm{C}_{2 v}$ symmetry; (b) correct $\mathrm{C}_{s}$ symmetry. [Color figure can be viewed in the online issue, which is available at www.interscience.wiley.com.]

Figure 1. Water dimer; (a) QM H-bond donor; (b) QM H-bond acceptor. [Color figure can be viewed in the online issue, which is available at www.interscience.wiley.com.]

to polarize the classical region. ${ }^{57}$ In the current work, we test the Drude polarizable water model with $\mathrm{QM} / \mathrm{MM}$ and try to assess the usefulness of this new model via application to simple test cases.

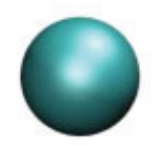

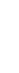


Table 2. Ab Initio QM/MM Results for the Water Dimer; for all Calculations the Classical Portion Employed the TIP4PEW Water Model.

\begin{tabular}{|c|c|c|c|c|c|c|}
\hline Method & Basis set & QM donor/acceptor & $\Delta E$ & $d(\mathrm{H} \cdots \mathrm{O})$ & $\angle \mathrm{O} \cdots \mathrm{HO}$ & $d(\mathrm{O} \cdots \mathrm{O})$ \\
\hline $\mathrm{AM}{ }^{9}$ & & Donor & 2.6 & 2.28 & 140.8 & \\
\hline $\mathrm{HF}$ & cc-pVTZ & Donor & 6.985 & 1.769 & 178.6 & 2.724 \\
\hline $\mathrm{HF}$ & aug-cc-pVTZ & Donor & 7.221 & 1.758 & 178.0 & 2.714 \\
\hline B3LYP & cc-pVTZ & Donor & 6.901 & 1.745 & 178.5 & 2.721 \\
\hline B3LYP & aug-cc-pVTZ & Donor & 7.362 & 1.722 & 177.6 & 2.701 \\
\hline MP2 & cc-pVTZ & Donor & 7.028 & 1.745 & 178.4 & 2.718 \\
\hline MP2 & aug-cc-pVTZ & Donor & 7.471 & 1.723 & 177.5 & 2.700 \\
\hline CCSD & cc-pVTZ & Donor & 6.923 & 1.751 & 178.5 & 2.722 \\
\hline CCSD & aug-cc-pVTZ & Donor & 7.290 & 1.734 & 177.7 & 2.706 \\
\hline $\mathrm{AM}^{9}{ }^{9}$ & & Acceptor & 3.0 & 2.15 & 163.8 & \\
\hline $\mathrm{HF}$ & cc-pVTZ & Acceptor & 6.992 & 1.799 & 177.8 & 2.756 \\
\hline $\mathrm{HF}$ & aug-cc-pVTZ & Acceptor & 6.840 & 1.812 & 177.6 & 2.768 \\
\hline B3LYP & cc-pVTZ & Acceptor & 6.663 & 1.811 & 177.4 & 2.767 \\
\hline B3LYP & aug-cc-pVTZ & Acceptor & 6.324 & 1.837 & 177.5 & 2.794 \\
\hline MP2 & cc-pVTZ & Acceptor & 6.716 & 1.810 & 177.0 & 2.766 \\
\hline MP2 & aug-cc-pVTZ & Acceptor & 6.445 & 1.833 & 176.4 & 2.789 \\
\hline CCSD & cc-pVTZ & Acceptor & 6.699 & 1.808 & 177.1 & 2.765 \\
\hline CCSD & aug-cc-pVTZ & Acceptor & 6.496 & 1.827 & 176.7 & 2.783 \\
\hline Drude/Drude & & & 5.243 & 1.860 & 173.4 & 2.813 \\
\hline TIP4PEW/TIP4PEW & & & 6.849 & 1.796 & 179.8 & 2.753 \\
\hline TIP3P/TIP3P & & & 6.832 & 1.785 & 173.3 & 2.756 \\
\hline LDA-MM $^{17}$ & $6-31 G^{*}$ & Donor & 7.136 & 1.765 & 179.2 & 2.742 \\
\hline LDA-MM $^{17}$ & $6-31 G^{*}$ & Acceptor & 7.139 & 1.736 & 179.4 & 2.715 \\
\hline BLYP-MM 17 & $6-31 G^{*}$ & Donor & 6.768 & 1.772 & 179.3 & 2.746 \\
\hline BLYP-MM $^{17}$ & $6-31 \mathrm{G}^{*}$ & Acceptor & 6.749 & 1.746 & 179.5 & 2.723 \\
\hline B3LYP-MM ${ }^{18}$ & $6-31 G^{*}$ & Donor & 6.92 & 1.77 & 179.1 & 2.75 \\
\hline B3LYP-MM ${ }^{18}$ & $6-31 G^{*}$ & Acceptor & 7.45 & 1.73 & 177.8 & 2.71 \\
\hline Extrapolated $^{74}$ & & & $5.02 \pm 0.05$ & & & 2.91 \\
\hline Focal point ${ }^{75}$ & & & $5.02 \pm 0.07$ & & & 2.91 \\
\hline Experimental $^{76,77}$ & & & $5.44 \pm 0.7$ & & $174 \pm 20$ & 2.98 \\
\hline
\end{tabular}

Binding energies, $\Delta E$, are reported in $\mathrm{kcal} / \mathrm{mol}$. Geometric parameters are reported in angstroms (bond distances) and degrees (bond angles).

\section{Computational Details}

\section{Hybrid QM/MM}

The Q-Chem/CHARMM QM/MM interface has been implemented at the source code level in the CHARMM and Q-Chem software packages. ${ }^{38,39,58}$ The premise behind this implementation is that each program can exist separately and interact with the other by passing information via files. This approach has both positive and negative aspects, but ultimately allows easy setup and application of QM/MM capability which has not always been the case. For example, this approach is different than the widely used GAMESS ${ }^{51,52} \mathrm{QM} / \mathrm{MM}$ interfaces in that no source code manipulations are needed to compile and run QM/MM calculations. A similar implementation has recently been reported using TURBOMOLE ${ }^{18,59}$ and CHARMM, but unlike that interface, all code needed to run QM/MM calculations exists within CHARMM and Q-Chem by default.

\section{Reaction Path Methods}

The study of chemical reactions has led to increased understanding of many important processes in fields ranging from organic chemistry to biochemistry and beyond. ${ }^{60-70}$ This importance has naturally led to the development of numerous computational methods to aid in the study of these processes. The intrinsic reaction coordinate (IRC) method has clearly been the most popular. ${ }^{61,62}$ The IRC method uses a known transition state to fully map a pathway connecting reactants and products. Although the IRC method has many advantages, its use of internal coordinates and the requirement that the transition state be known a priori limits its application in the study of enzyme catalyzed reactions. In response to these 
Table 3. Ab Initio QM/MM Results for the Water Dimer; for all Calculations the Classical Portion Employed the TIP3P Water Model.

\begin{tabular}{|c|c|c|c|c|c|c|}
\hline Method & Basis set & QM donor/acceptor & $\Delta E$ & $d(\mathrm{H} \cdots \mathrm{O})$ & $\angle \mathrm{O} \cdots \mathrm{HO}$ & $d(\mathrm{O} \cdots \mathrm{O})$ \\
\hline $\mathrm{AM} 1^{9}$ & & Donor & 2.6 & 2.28 & 140.8 & \\
\hline $\mathrm{HF}$ & cc-pVTZ & Donor & 7.784 & 1.743 & 179.9 & 2.699 \\
\hline $\mathrm{HF}$ & aug-cc-pVTZ & Donor & 8.064 & 1.732 & 179.5 & 2.689 \\
\hline B3LYP & cc-pVTZ & Donor & 7.709 & 1.723 & 179.9 & 2.700 \\
\hline B3LYP & aug-cc-pVTZ & Donor & 8.197 & 1.705 & 179.1 & 2.685 \\
\hline MP2 & cc-pVTZ & Donor & 7.819 & 1.724 & 179.8 & 2.698 \\
\hline MP2 & aug-cc-pVTZ & Donor & 8.322 & 1.705 & 178.9 & 2.683 \\
\hline CCSD & cc-pVTZ & Donor & 7.704 & 1.729 & 179.9 & 2.701 \\
\hline CCSD & aug-cc-pVTZ & Donor & 8.128 & 1.714 & 179.1 & 2.687 \\
\hline $\mathrm{AM}^{9}{ }^{9}$ & & Acceptor & 3.0 & 2.15 & 163.8 & \\
\hline $\mathrm{HF}$ & cc-pVTZ & Acceptor & 6.815 & 1.793 & 177.9 & 2.768 \\
\hline $\mathrm{HF}$ & aug-cc-pVTZ & Acceptor & 6.672 & 1.804 & 178.0 & 2.778 \\
\hline B3LYP & cc-pVTZ & Acceptor & 6.487 & 1.805 & 177.1 & 2.778 \\
\hline B3LYP & aug-cc-pVTZ & Acceptor & 6.173 & 1.828 & 178.2 & 2.801 \\
\hline MP2 & cc-pVTZ & Acceptor & 6.537 & 1.802 & 179.0 & 2.776 \\
\hline MP2 & aug-cc-pVTZ & Acceptor & 6.281 & 1.823 & 179.2 & 2.796 \\
\hline CCSD & cc-pVTZ & Acceptor & 6.523 & 1.801 & 178.8 & 2.775 \\
\hline CCSD & aug-cc-pVTZ & Acceptor & 6.331 & 1.818 & 179.0 & 2.792 \\
\hline Drude/Drude & & & 5.243 & 1.860 & 173.4 & 2.813 \\
\hline TIP4PEW/TIP4PEV & & & 6.849 & 1.796 & 179.8 & 2.753 \\
\hline TIP3P/TIP3P & & & 6.832 & 1.785 & 173.3 & 2.756 \\
\hline LDA-MM ${ }^{17}$ & $6-31 G^{*}$ & Donor & 7.136 & 1.765 & 179.2 & 2.742 \\
\hline LDA-MM ${ }^{17}$ & $6-31 G^{*}$ & Acceptor & 7.139 & 1.736 & 179.4 & 2.715 \\
\hline BLYP-MM $^{17}$ & $6-31 G^{*}$ & Donor & 6.768 & 1.772 & 179.3 & 2.746 \\
\hline BLYP-MM $^{17}$ & $6-31 G^{*}$ & Acceptor & 6.749 & 1.746 & 179.5 & 2.723 \\
\hline B3LYP-MM 18 & $6-31 G^{*}$ & Donor & 6.92 & 1.77 & 179.1 & 2.75 \\
\hline B3LYP-MM ${ }^{18}$ & $6-31 G^{*}$ & Acceptor & 7.45 & 1.73 & 177.8 & 2.71 \\
\hline Extrapolated $^{74}$ & & & $5.02 \pm 0.05$ & & & 2.91 \\
\hline Focal point ${ }^{75}$ & & & $5.02 \pm 0.07$ & & & 2.91 \\
\hline Experimental $^{76,77}$ & & & $5.44 \pm 0.7$ & & $174 \pm 20$ & 2.98 \\
\hline
\end{tabular}

Binding energies, $\Delta E$, are reported in $\mathrm{kcal} / \mathrm{mol}$. Geometric parameters are reported in angstroms (bond distances) and degrees (bond angles).

limitations, numerous chain-of-replica pathway methods have been developed. ${ }^{64-67}$ These methods typically eliminate the expensive analytic Hessian computation by approximations based upon only gradient information. In addition, Cartesian coordinates are more commonly employed to study biological systems, which avoids the high cost of coordinate transformations.

In addition to the standard QM/MM interface, we have added the ability to employ CHARMM's recently added parallel/parallel replica path method (RPM) and nudged elastic band (NEB) method. ${ }^{46,47}$ In our current scheme, these methods work by creating $n$ directories, where $n$ is the number of points used in the pathway calculation. Each QM calculation is then passed to a different processor, or group of processors, as dictated by the controlling CHARMM process. After the completion of an entire pathway step, CHARMM receives and processes all necessary information (gradients and energies) and then takes the next step of the pathway simulation/optimization.

\section{Results and Discussion}

To confirm the accuracy of our QM/MM interface, we have constructed and evaluated six test cases at multiple levels of theory, with various basis sets, and employing different classical water models. The first three of these are commonly employed to test QM/MM implementations and include the water dimer, waterchloride anion complex, and water-sodium cation complex. ${ }^{9,17,18}$ In addition, the butane torsional potential and $\mathrm{S}_{N} 2$ reaction between $\mathrm{OH}^{-}$and $\mathrm{CH}_{3} \mathrm{~F}$ have been examined using the parallel/parallel replica path method to confirm the correctness of our QM/MM 
Table 4. Ab Initio QM/MM Results for the Water Dimer; for all Calculations the Classical Portion Employed the Polarizable Drude Water Model.

\begin{tabular}{|c|c|c|c|c|c|c|}
\hline Method & Basis set & QM donor/acceptor & $\Delta E$ & $d(\mathrm{H} \cdots \mathrm{O})$ & $\angle \mathrm{O} \cdots \mathrm{HO}$ & $d(\mathrm{O} \cdots \mathrm{O})$ \\
\hline $\mathrm{AM}{ }^{9}$ & & Donor & 2.6 & 2.28 & 140.8 & \\
\hline $\mathrm{HF}$ & cc-pVTZ & Donor & 6.920 & 1.809 & 175.1 & 2.762 \\
\hline $\mathrm{HF}$ & aug-cc-pVTZ & Donor & 7.367 & 1.787 & 174.5 & 2.742 \\
\hline B3LYP & cc-pVTZ & Donor & 6.977 & 1.775 & 174.7 & 2.752 \\
\hline B3LYP & aug-cc-pVTZ & Donor & 7.908 & 1.733 & 174.1 & 2.713 \\
\hline MP2 & cc-pVTZ & Donor & 7.160 & 1.771 & 174.9 & 2.746 \\
\hline MP2 & aug-cc-pVTZ & Donor & 8.233 & 1.722 & 174.1 & 2.704 \\
\hline CCSD & cc-pVTZ & Donor & 6.955 & 1.783 & 175.0 & 2.755 \\
\hline CCSD & aug-cc-pVTZ & Donor & 7.776 & 1.744 & 174.3 & 2.721 \\
\hline $\mathrm{AM}^{9}{ }^{9}$ & & Acceptor & 3.0 & 2.15 & 163.8 & \\
\hline $\mathrm{HF}$ & cc-pVTZ & Acceptor & 6.153 & 1.880 & 174.6 & 2.834 \\
\hline $\mathrm{HF}$ & aug-cc-pVTZ & Acceptor & 6.044 & 1.891 & 174.2 & 2.844 \\
\hline B3LYP & cc-pVTZ & Acceptor & 5.845 & 1.892 & 174.2 & 2.846 \\
\hline B3LYP & aug-cc-pVTZ & Acceptor & 5.582 & 1.916 & 173.7 & 2.870 \\
\hline MP2 & cc-pVTZ & Acceptor & 5.888 & 1.890 & 173.8 & 2.843 \\
\hline MP2 & aug-cc-pVTZ & Acceptor & 5.688 & 1.912 & 173.2 & 2.864 \\
\hline CCSD & cc-pVTZ & Acceptor & 5.873 & 1.889 & 173.9 & 2.843 \\
\hline CCSD & aug-cc-pVTZ & Acceptor & 5.728 & 1.906 & 173.5 & 2.859 \\
\hline Drude/Drude & & & 5.243 & 1.860 & 173.4 & 2.813 \\
\hline TIP4PEW/TIP4PEI & & & 6.849 & 1.796 & 179.8 & 2.753 \\
\hline TIP3P/TIP3P & & & 6.832 & 1.785 & 173.3 & 2.756 \\
\hline LDA-MM $^{17}$ & $6-31 G^{*}$ & Donor & 7.136 & 1.765 & 179.2 & 2.742 \\
\hline LDA-MM $^{17}$ & $6-31 G^{*}$ & Acceptor & 7.139 & 1.736 & 179.4 & 2.715 \\
\hline BLYP-MM $^{17}$ & $6-31 G^{*}$ & Donor & 6.768 & 1.772 & 179.3 & 2.746 \\
\hline BLYP-MM $^{17}$ & $6-31 G^{*}$ & Acceptor & 6.749 & 1.746 & 179.5 & 2.723 \\
\hline B3LYP-MM ${ }^{18}$ & $6-31 G^{*}$ & Donor & 6.92 & 1.77 & 179.1 & 2.75 \\
\hline B3LYP-MM ${ }^{18}$ & $6-31 G^{*}$ & Acceptor & 7.45 & 1.73 & 177.8 & 2.71 \\
\hline Extrapolated ${ }^{74}$ & & & $5.02 \pm 0.05$ & & & 2.91 \\
\hline Focal point ${ }^{75}$ & & & $5.02 \pm 0.07$ & & & 2.91 \\
\hline Experimental $^{76,77}$ & & & $5.44 \pm 0.7$ & & $174 \pm 20$ & 2.98 \\
\hline
\end{tabular}

Binding energies, $\Delta E$, are reported in $\mathrm{kcal} / \mathrm{mol}$. Geometric parameters are reported in angstroms (bond distances) and degrees (bond angles).

pathway implementation. Finally, we have used the extensively studied chorismate mutase enzyme to test the effectiveness and efficiency of our implementation on a fully solvated biological system. In all cases, previously reported experimental and theoretical results will be used for comparison.

All full QM Hartree-Fock (HF), density functional theory (DFT), and perturbation theory (RIMP2, MP2) computations were performed with the Q-Chem software package. ${ }^{38}$ All hybrid QM/MM minimizations employed CHARMM's adopted basis NewtonRaphson (ABNR) method ${ }^{39}$ and were run until the RMS gradient reached $0.02 \mathrm{kcal} / \mathrm{mol} / \AA\left(1.1 \times 10^{-4}\right.$ hartree/bohr $)$ or smaller. To facilitate comparison with previous theoretical results, counterpoise (BSSE) corrections were not performed. This has been shown to be approximately $1-2 \mathrm{kcal} / \mathrm{mol}$ for the water-cation test case. ${ }^{71}$ All parameters for the QM/MM computations were taken, without modification, from the standard CHARMM27 parameter file ${ }^{72}$ except for sodium parameters which have been recently updated. $^{73}$

\section{Water Dimer}

The water dimer complex has been commonly used to evaluate QM/MM interfaces. ${ }^{9,17,18}$ As is standard practice, the system is partitioned into two possible configurations: the QM water can be either a hydrogen bond donor or acceptor (Fig. 1 and Tables 1-4). For the classical (MM) portion of this test case, we employed three water models. The TIP3P model (which includes the average effects of water polarization), ${ }^{78,79}$ TIP4PEW (which has been modified to improve dipole treatment), ${ }^{80}$ and the 5 -site Drude polarizable model ${ }^{57}$ were all used. In addition, we performed QM optimizations of this complex to have data for comparison. 
Table 5. Ab initio Results for the Water. . Chloride Complex.

\begin{tabular}{llcccc}
\hline Method & \multicolumn{1}{c}{ Basis set } & $\Delta E$ & $d\left(\mathrm{O} \cdots \mathrm{Cl}^{-}\right)$ & $\angle \mathrm{OH} \cdots \mathrm{Cl}^{-}$ & $d\left(\mathrm{H}^{2} \mathrm{Cl}^{-}\right)$ \\
\hline HF & cc-pVTZ & 13.716 & 3.249 & 159.9 & 2.334 \\
HF & cc-pVQZ & 12.937 & 3.266 & 161.2 & 2.347 \\
HF & aug-cc-pVTZ & 12.089 & 3.278 & 161.2 & 2.359 \\
HF & aug-cc-pVQZ & 12.056 & 3.272 & 162.0 & 2.353 \\
B3LYP & cc-pVTZ & 16.993 & 3.126 & 166.1 & 2.155 \\
B3LYP & cc-pVQZ & 16.025 & 3.132 & 167.2 & 2.160 \\
B3LYP & aug-cc-pVTZ & 14.696 & 3.137 & 165.3 & 2.160 \\
B3LYP & aug-cc-pVQZ & 14.764 & 3.136 & 167.5 & 2.162 \\
MP2 & cc-pVTZ & 17.500 & 3.086 & 165.7 & 2.144 \\
MP2 & cc-pVQZ & 16.629 & 3.091 & 166.5 & 2.124 \\
MP2 & aug-cc-pVTZ & 16.049 & 3.095 & 168.9 & 2.117 \\
MP2 & aug-cc-pVQZ & 15.953 & 3.090 & 166.4 & 2.116 \\
LDA $^{17}$ & 6-31G* & 22.10 & 3.075 & 161.8 & 2.044 \\
BLYP & 6-31G* & 15.98 & 3.161 & 157.8 & 2.203 \\
B3LYP & 6-31G* & 17.42 & 3.17 & 158.8 & 2.22 \\
MP4 $^{81}$ & aug-cc-pVTZ & 15.4 & & & \\
MP4 $^{81}$ & aug-cc-pVTZ(BSSE) & 14.5 & & & \\
Experimental $^{82}$ & & 13.4 & & & \\
\hline
\end{tabular}

Binding energies, $\Delta E$, are reported in $\mathrm{kcal} / \mathrm{mol}$. Geometric parameters are reported in angstroms (bond distances) and degrees (bond angles).

On examining our results, we find that hybrid QM/MM calculations that have the QM water as the acceptor generally agree better with their full QM references than do calculations with QM water as the donor. This is a common result for all three water models employed; however, the Drude model performs better in this respect compared to both TIP3P and TIP4PEW. All HF QM/MM calculations significantly overestimated the binding energy of the water dimer, whereas B3LYP, MP2, and CCSD did a much better job of reproducing the full QM and experimental results. Structural parameters were typically underestimated for both QM donor and QM acceptor cases; however, QM acceptor calculations were significantly better. For example, $\mathrm{O} \cdots \mathrm{O}$ distances were on the order of 0.1-0.3 $\AA$ shorter in donor cases when compared with acceptor cases.

Table 6. Ab Initio QM/MM Results for the Water . . Chloride Complex; for all Calculations the Classical Portion Employed the TIP4PEW Water Model.

\begin{tabular}{|c|c|c|c|c|c|}
\hline Method & Basis set & $\Delta E$ & $d\left(\mathrm{O} \cdots \mathrm{Cl}^{-}\right)$ & $\angle \mathrm{OH} \cdots \mathrm{Cl}^{-}$ & $d\left(\mathrm{H} \cdots \mathrm{Cl}^{-}\right)$ \\
\hline $\mathrm{HF}$ & cc-pVTZ & 14.279 & 3.127 & 111.1 & 2.652 \\
\hline $\mathrm{HF}$ & aug-cc-pVTZ & 13.853 & 3.156 & 111.3 & 2.680 \\
\hline B3LYP & cc-pVTZ & 14.269 & 3.129 & 111.0 & 2.655 \\
\hline B3LYP & aug-cc-pVTZ & 13.571 & 3.172 & 111.4 & 2.694 \\
\hline MP2 & cc-pVTZ & 12.037 & 3.413 & 112.8 & 2.927 \\
\hline MP2 & aug-cc-pVTZ & 13.691 & 3.166 & 111.4 & 2.688 \\
\hline CCSD & cc-pVTZ & 14.274 & 3.128 & 111.1 & 2.653 \\
\hline CCSD & aug-cc-pVTZ & 13.760 & 3.162 & 111.4 & 2.685 \\
\hline LDA-MM $^{17}$ & $6-31 G^{*}$ & 14.18 & 3.237 & 134.7 & 2.474 \\
\hline BLYP-MM ${ }^{17}$ & $6-31 G^{*}$ & 14.18 & 3.236 & 134.9 & 2.474 \\
\hline B3LYP-MM ${ }^{18}$ & $6-31 G^{*}$ & 16.98 & 3.02 & 163.6 & 2.05 \\
\hline MP4 $4^{81}$ & aug-cc-pVTZ & 15.4 & & & \\
\hline $\mathrm{MP}^{81}$ & aug-cc-pVTZ(BSSE) & 14.5 & & & \\
\hline Experimental $^{82}$ & & 13.4 & & & \\
\hline
\end{tabular}

Binding energies, $\Delta E$, are reported in $\mathrm{kcal} / \mathrm{mol}$. Geometric parameters are reported in angstroms (bond distances) and degrees (bond angles). 
Table 7. Ab Initio QM/MM Results for the Water . . Chloride Complex; for all Calculations the Classical Portion Employed the TIP3P Water Model.

\begin{tabular}{|c|c|c|c|c|c|}
\hline Method & Basis set & $\Delta E$ & $d\left(\mathrm{O} \cdots \mathrm{Cl}^{-}\right)$ & $\angle \mathrm{OH} \cdots \mathrm{Cl}^{-}$ & $d\left(\mathrm{H} \cdots \mathrm{Cl}^{-}\right)$ \\
\hline $\mathrm{HF}$ & cc-pVTZ & 17.531 & 3.095 & 126.30 & 2.418 \\
\hline $\mathrm{HF}$ & aug-cc-pVTZ & 17.101 & 3.121 & 116.5 & 2.568 \\
\hline B3LYP & cc-pVTZ & 17.502 & 3.096 & 123.9 & 2.448 \\
\hline B3LYP & aug-cc-pVTZ & 16.644 & 3.139 & 116.4 & 2.587 \\
\hline MP2 & cc-pVTZ & 17.519 & 3.097 & 125.3 & 2.432 \\
\hline MP2 & aug-cc-pVTZ & 16.832 & 3.132 & 116.4 & 2.580 \\
\hline CCSD & cc-pVTZ & 17.525 & 3.096 & 125.7 & 2.427 \\
\hline CCSD & aug-cc-pVTZ & 16.955 & 3.128 & 116.5 & 2.575 \\
\hline LDA-MM ${ }^{17}$ & $6-31 G^{*}$ & 14.18 & 3.237 & 134.7 & 2.474 \\
\hline BLYP-MM ${ }^{17}$ & $6-31 G^{*}$ & 14.18 & 3.236 & 134.9 & 2.474 \\
\hline B3LYP-MM ${ }^{18}$ & $6-31 G^{*}$ & 16.98 & 3.02 & 163.6 & 2.05 \\
\hline $\mathrm{MP} 4^{81}$ & aug-cc-pVTZ & 15.4 & & & \\
\hline $\mathrm{MP} 4^{81}$ & aug-cc-pVTZ(BSSE) & 14.5 & & & \\
\hline Experimental $^{82}$ & & 13.4 & & & \\
\hline
\end{tabular}

Binding energies, $\Delta E$, are reported in $\mathrm{kcal} / \mathrm{mol}$. Geometric parameters are reported in angstroms (bond distances) and degrees (bond angles).

\section{Water-Anion Complex}

The water-chloride anion complex is a well known failure of the semiempirical (AM1) QM/MM methodology. $9,17,18$ For example, Field et al. ${ }^{9}$ showed that treating the water with a classical force field resulted in an incorrect symmetry prediction $\left(\mathrm{C}_{2 v}\right)$, while the true global minimum is $\mathrm{C}_{s}$. When the water molecule is treated quantum mechanically (even with AM1) the correct symmetry is predicted, although the binding energy is significantly underestimated (Tables 5-9).
We performed $a b$ initio calculations as references for our QM/MM test case. The highest level of theory employed was MP2/aug-cc-pVQZ, which yielded a binding energy of 15.95 $\mathrm{kcal} / \mathrm{mol}$ (non-BSSE, ZPE corrected) and is in good agreement with previous MP4/aug-cc-pVTZ calculations ( $15.4 \mathrm{kcal} / \mathrm{mol}) .{ }^{81}$

We observed incorrect symmetry predictions when using the TIP3P and TIP4PEW water models (Fig. 2). In both cases, a $\mathrm{C}_{2 v}$ structure was obtained for the global minimum (Fig. 2a). However, application of the polarizable Drude water model correctly predicted a $C_{s}$ global minimum (Fig. 2b). On average, the Drude QM/MM

Table 8. Ab Initio QM/MM Results for the Water . . Chloride Complex; for all Calculations the Classical Portion Employed the Polarizable Drude Water Model.

\begin{tabular}{|c|c|c|c|c|c|}
\hline Method & Basis set & $\Delta E$ & $d\left(\mathrm{O} \cdots \mathrm{Cl}^{-}\right)$ & $\angle \mathrm{OH} \cdots \mathrm{Cl}^{-}$ & $d\left(\mathrm{H} \cdots \mathrm{Cl}^{-}\right)$ \\
\hline $\mathrm{HF}$ & cc-pVTZ & 15.198 & 3.130 & 167.4 & 2.189 \\
\hline $\mathrm{HF}$ & aug-cc-pVTZ & 14.518 & 3.192 & 166.8 & 2.253 \\
\hline B3LYP & cc-pVTZ & 15.110 & 3.166 & 167.6 & 2.224 \\
\hline B3LYP & aug-cc-pVTZ & 13.956 & 3.217 & 165.7 & 2.281 \\
\hline MP2 & cc-pVTZ & 15.137 & 3.163 & 167.7 & 2.221 \\
\hline MP2 & aug-cc-pVTZ & 14.186 & 3.209 & 166.1 & 2.272 \\
\hline CCSD & cc-pVTZ & 15.154 & 3.162 & 167.7 & 2.220 \\
\hline CCSD & aug-cc-pVTZ & 14.344 & 3.203 & 166.3 & 2.265 \\
\hline LDA-MM $^{17}$ & $6-31 G^{*}$ & 14.18 & 3.237 & 134.7 & 2.474 \\
\hline BLYP-MM ${ }^{17}$ & $6-31 G^{*}$ & 14.18 & 3.236 & 134.9 & 2.474 \\
\hline B3LYP-MM ${ }^{18}$ & $6-31 G^{*}$ & 16.98 & 3.02 & 163.6 & 2.05 \\
\hline MP4 $4^{81}$ & aug-cc-pVTZ & 15.4 & & & \\
\hline $\mathrm{MP}^{81}$ & aug-cc-pVTZ(BSSE) & 14.5 & & & \\
\hline Experimental $^{82}$ & & 13.4 & & & \\
\hline
\end{tabular}

Binding energies, $\Delta E$, are reported in $\mathrm{kcal} / \mathrm{mol}$. Geometric parameters are reported in angstroms (bond distances) and degrees (bond angles). 
Table 9. Ab Initio QM/MM Results for the Water . . Chloride Complex; for all Calculations the Classical Portion Employed the Standard CHARMM Chloride Parameters (i.e., QM Water).

\begin{tabular}{|c|c|c|c|c|c|}
\hline Method & Basis set & $\Delta E$ & $d\left(\mathrm{O} \cdots \mathrm{Cl}^{-}\right)$ & $\angle \mathrm{OH} \cdots \mathrm{Cl}^{-}$ & $d\left(\mathrm{H} \cdots \mathrm{Cl}^{-}\right)$ \\
\hline $\mathrm{HF}$ & cc-pVTZ & 17.390 & 3.007 & 166.6 & 2.060 \\
\hline $\mathrm{HF}$ & aug-cc-pVTZ & 17.869 & 2.998 & 167.8 & 2.045 \\
\hline B3LYP & cc-pVTZ & 17.374 & 3.008 & 166.9 & 2.037 \\
\hline B3LYP & aug-cc-pVTZ & 18.131 & 2.993 & 168.8 & 2.015 \\
\hline MP2 & cc-pVTZ & 17.536 & 3.006 & 167.1 & 2.037 \\
\hline MP2 & aug-cc-pVTZ & 18.356 & 2.992 & 169.2 & 2.011 \\
\hline CCSD & cc-pVTZ & 17.245 & 3.009 & 166.9 & 2.051 \\
\hline CCSD & aug-cc-pVTZ & 17.938 & 2.997 & 168.7 & 2.026 \\
\hline LDA-MM ${ }^{17}$ & $6-31 G^{*}$ & 14.18 & 3.237 & 134.7 & 2.474 \\
\hline BLYP-MM $^{17}$ & $6-31 G^{*}$ & 14.18 & 3.236 & 134.9 & 2.474 \\
\hline B3LYP-MM ${ }^{18}$ & $6-31 G^{*}$ & 16.98 & 3.02 & 163.6 & 2.05 \\
\hline $\mathrm{MP}^{81}$ & aug-cc-pVTZ & 15.4 & & & \\
\hline $\mathrm{MP} 4^{81}$ & aug-cc-pVTZ(BSSE) & 14.5 & & & \\
\hline Experimental $^{82}$ & & 13.4 & & & \\
\hline
\end{tabular}

Binding energies, $\Delta E$, are reported in $\mathrm{kcal} / \mathrm{mol}$. Geometric parameters are reported in angstroms (bond distances) and degrees (bond angles).

calculations resulted in structural differences of less than $0.1 \AA$ in bond and $2-3^{\circ}$ in angle parameters, when compared with their full QM references (Tables 5-9). Although binding energies obtained via these calculations were underestimated by $1-3 \mathrm{kcal} / \mathrm{mol}$, the fact that the structures were, both qualitatively and quantitatively, predicted correctly shows the utility of polarizable models when charged QM regions are interacting with MM environments.

\section{Water-Cation Complex}

The water-sodium cation complex (Fig. 3) is another well known example of where one can run into problems employing semiempirical QM/MM methodology. It has been suggested that since semiempirical methods use only valence electrons to describe metal atoms, it is basically reduced to a point charge model. ${ }^{9}$ Additionally, many metal atoms have no semiempirical parameters and leave no option but to employ ab initio QM/MM methods to examine systems such as metalloenzymes.

The use of all three water models resulted in slightly overestimated binding energies, when compared with full QM references (Tables 10-14). However, structural parameters obtained from these models were quite close to the QM results. The use of a QM water and classical sodium also showed a slight overestimation of binding energy and quite similar structural parameters when compared with full QM calculations. It should be noted that Drude and/or van der Waals parameters can be easily optimized to give better agreement with full QM results; however, no such adjustments were made in the current study.

\section{QM/MM Replica Path Example: Torsional Potential of Butane}

The conformational analysis of alkanes has long been of interest to chemists. ${ }^{85}$ The fundamental understanding of alkane potentials is not only of interest to industrial and polymer chemists, but also holds much value to biophysicists as mono- and bilayer behavior is largely governed by these interactions. ${ }^{86-88}$ As recently as 1997 , debate over an accurate value of butane's torsional potential was ongoing. A detailed ab initio study revealed extrapolated values of $3.31 \mathrm{kcal} / \mathrm{mol}\left(120^{\circ} \mathrm{TS}\right), 0.62 \mathrm{kcal} / \mathrm{mol}$ (Anti-Gauche), and $5.40 \mathrm{kcal} / \mathrm{mol}$ (Anti-Syn TS) which appears to be an accurate prediction. ${ }^{89}$

To test the implementation of the replica path method, with Q-Chem as the quantum engine, we mapped the complete torsional potential of butane employing various QM and QM/MM levels of theory (Table 15, Figs. 4-6). The standard single link atom (SLA) approach was applied. ${ }^{90-93}$ The EXGR (exclusion of QM/MM electrostatic interactions of the MM host group) method ${ }^{8}$ was also employed. These two QM/MM schemes were compared to full QM replica path calculations, standard QM optimizations and transition state searches, and double link atom with Gaussian blur (DLA/DGMM) ${ }^{13}$ QM/MM minimizations.

In general, the SLA and EXGR QM/MM methods underestimated the Anti-Syn and Anti-Gauche energy differences while the Anti- $120^{\circ}$ TS was treated fairly accurately. These results agreed well with other, more sophisticated, link atom treatments (DLA/DGMM). This confirms the results of a previous study that found that the type of link atom treatment plays a relatively minor role when examining QM/MM reaction pathways. ${ }^{94}$

\section{QM Replica Path Example: $\mathrm{OH}^{-}+\mathrm{CH}_{3} \mathrm{~F} \rightarrow \mathrm{CH}_{3} \mathrm{OH}+\mathrm{F}^{-}$}

Gas-phase $\mathrm{S}_{N} 2$, nucleophilic substitution, reactions are not only chemically important reaction types but are also commonly used as benchmarks to examine the validity of computational methods. ${ }^{95-98}$

Recent high level $a b$ initio studies of this reaction have yielded results showing that the reaction does not proceed via a normal 


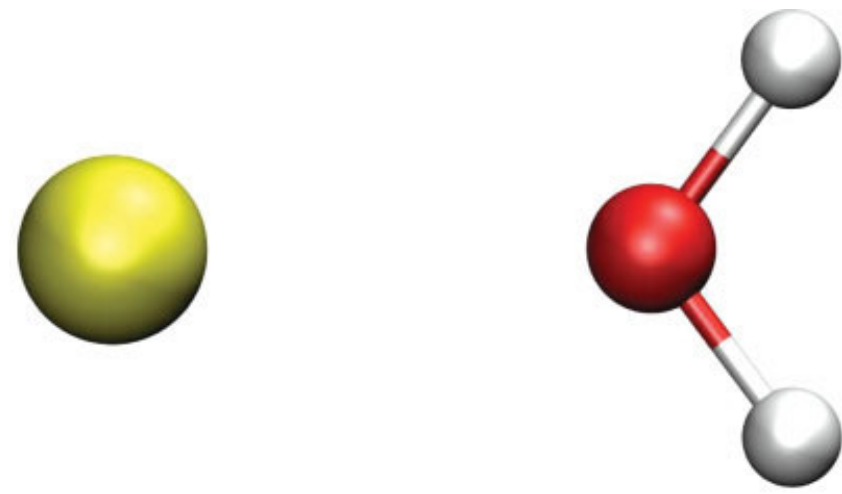

Figure 3. Water $\cdots \mathrm{Na}^{+}$complex. [Color figure can be viewed in the online issue, which is available at www.interscience.wiley.com.]

colinear transition state. ${ }^{97,98}$

$$
\mathrm{OH}^{-}+\mathrm{CH}_{3} \mathrm{~F} \rightarrow \mathrm{CH}_{3} \mathrm{OH}+\mathrm{F}^{-}
$$

IRC calculations confirmed that no backside ion-molecule complex exists. Additional work has been done to dynamically examine the "deep potential energy minimum" that governs this reaction and to describe the indirect reaction path that results in the intracomplex reaction occurring. ${ }^{96}$

This reaction has also been used to benchmark various DFT methods. ${ }^{95}$ This has shown that extreme care must be taken when using DFT and even HF methods to determine reaction barriers. Post-HF methods (i.e., MP2, CCSD) are needed to accurately describe dispersion forces. These forces commonly play a large role in determining reaction energetics and therefore must be treated correctly to ensure accurate barrier heights.

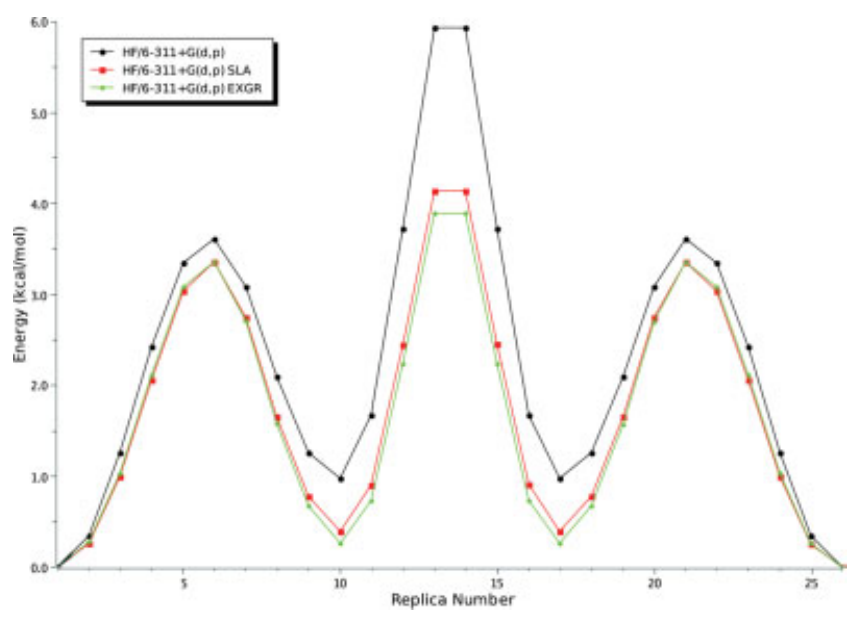

Figure 4. Full $\mathrm{QM}$ and $\mathrm{QM} / \mathrm{MM}$ results for the butane torsional potential. QM/MM link atom treatments employed the SLA and EXGR methods. All QM and QM/MM calculations were run at the $\mathrm{HF} / 6-311+\mathrm{G}(\mathrm{d}, \mathrm{p})$ level of theory with energies reported in $\mathrm{kcal} / \mathrm{mol}$. [Color figure can be viewed in the online issue, which is available at www.interscience.wiley.com.]

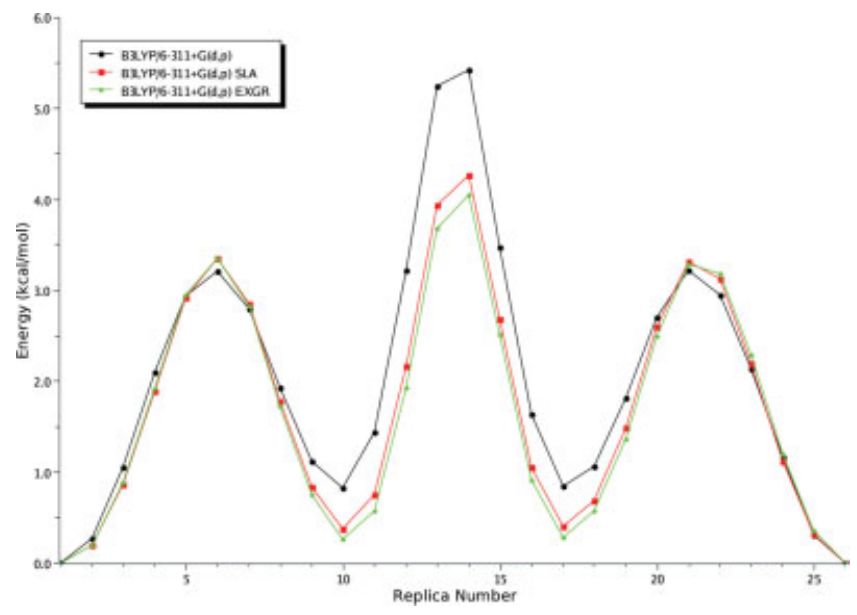

Figure 5. Full QM and QM/MM results for the butane torsional potential. QM/MM link atom treatments employed the SLA and EXGR methods. All QM and QM/MM calculations were run at the B3LYP/6$311+\mathrm{G}(\mathrm{d}, \mathrm{p})$ level of theory with energies reported in $\mathrm{kcal} / \mathrm{mol}$. [Color figure can be viewed in the online issue, which is available at www.interscience.wiley.com.]

A common scheme used to examine QM/MM reaction paths is the so-called forced transition method. This procedure involves restraining coordinates that appear to control the reaction (i.e., distances). In the past this has been an effective tool for mapping many chemical and biochemical reactions. ${ }^{99}$ However, it is not hard to imagine cases where this procedure can become overly complex and in some cases impossible. The reaction in question here is one such case. Determining only two distances that force this reaction to occur would be problematic at best and impossible at worst. In complex situations, alternative methods for examining reaction paths are attractive.

Using the replica path method at the HF, B3LYP, and MP2 levels of theory, we mapped the indirect reaction path and determined the forward and reverse barrier heights (Table 16, Fig. 7). Our results are in excellent agreement with previous computational studies and more importantly yielded transition state analogs that had only the correct negative eigenvalue. This is an important result as we have now shown that an intelligent use of the replica path method can effectively and efficiently approximate minimum energy pathways of complex reactions.

\section{Chorismate Mutase}

The Claisen rearrangement catalyzed by chorismate mutase has been the subject of many experimental and computational studies in recent years. ${ }^{100-104}$ Researchers are intersted in this reaction primarily because of its key role in the shikimate pathway of bacteria, fungi, and other higher plants. ${ }^{105,106}$ Another point of interest is its role in benchmarking many QM/MM methods. As a test case for our current QM/MM implementation, we computed the activation and reaction energies of the Bacillus Subtilis catalyzed Claisen rearrangement of chorismate to prephenate (Table 17, Fig. 8). We also examined the geometries of the reactant, transition state analog (TSA) and product, comparing these to previously published QM/MM structures 
Table 10. Ab Initio Results for the Water. . Sodium Complex.

\begin{tabular}{|c|c|c|c|c|}
\hline Method & Basis set & $\Delta E$ & $d\left(\mathrm{O} \cdots \mathrm{Na}^{+}\right)$ & $\angle \mathrm{HO} \cdots \mathrm{Na}^{+}$ \\
\hline $\mathrm{HF}$ & cc-pVTZ & 25.455 & 2.240 & 127.2 \\
\hline $\mathrm{HF}$ & cc-pVQZ & 24.567 & 2.235 & 127.1 \\
\hline $\mathrm{HF}$ & $6-311++\mathrm{G}(3 \mathrm{df}, 3 \mathrm{pd})$ & 24.265 & 2.227 & 127.2 \\
\hline B3LYP & cc-pVTZ & 27.326 & 2.223 & 127.9 \\
\hline B3LYP & cc-pVQZ & 25.702 & 2.223 & 127.5 \\
\hline B3LYP & $6-311++G(3 d f, 3 p d)$ & 24.582 & 2.213 & 127.7 \\
\hline MP2 & cc-pVTZ & 26.458 & 2.273 & 127.8 \\
\hline MP2 & cc-pVQZ & 23.663 & 2.276 & 128.0 \\
\hline MP2 & $6-311++\mathrm{G}(3 \mathrm{df}, 3 \mathrm{pd})$ & 22.754 & 2.272 & 128.0 \\
\hline $\mathrm{LDA}^{17}$ & $6-31 G^{*}$ & 34.41 & 2.118 & 127.1 \\
\hline BLYP $^{17}$ & $6-31 G^{*}$ & 30.86 & 2.168 & 127.4 \\
\hline $\operatorname{CCSD}(\mathrm{T})^{83}$ & cc-pCVTZ & 23.6 & 2.226 & \\
\hline Experimental $^{84}$ & & 24.0 & & \\
\hline
\end{tabular}

Binding energies, $\Delta E$, are reported in $\mathrm{kcal} / \mathrm{mol}$. Geometric parameters are reported in angstroms (bond distances) and degrees (bond angles).

(Table 18). Using Q-Chem's highly efficient algorithms, we have characterized the reaction profile of this important reaction at the highest level of theory published to date.

Using the reactants and products, with chorismate and prephenate in the active site, from a previous study, ${ }^{46}$ we employed the $\mathrm{QM} / \mathrm{MM}$ replica path method to optimize the fully solvated systems and transition state analogs at the QM/MM HF/4-31G/C22, HF/631G(d)/C22, HF/6-31+G(d)/C22, B3LYP/6-31G(d)/C22, B3LYP/ 6-31+G(d)/C22, RIMP2/6-31G(d)/C22, RIMP2/6-31+G(d)/C22, MP2/6-31G(d)/C22, and MP2/6-31+G(d)/C22 levels of theory. To study this reaction, most researchers have employed HF or semiempirical levels of QM theory with some applying higher level vacuum based corrections. ${ }^{99,107-109}$
All pathways were optimized by a novel application of the replica path method in conjunction with the use of distance restraints (CHARMM's RES Distance facility). This allowed the use of the standard chorismate mutase reaction coordinate $\left(\delta=\mathrm{d}_{\mathrm{C} 1-\mathrm{C} 9}-\right.$ $\mathrm{d}_{\mathrm{C} 3-\mathrm{O} 7}$, Fig. 8) while still utilizing the replica path method to prevent hysteresis problems. After pathway optimization, all HF and B3LYP structures were confirmed to be either stationary or first order saddle points via analytic hessian calculations in the fixed field of point charges. These calculations were performed outside of the QM/MM interface with Q-Chem 3.0.

Using HF/6-31+G(d), we computed an energy barrier $\left(\Delta E^{\ddagger}\right)$ of $26.2 \mathrm{kcal} / \mathrm{mol}$ and an energy of reaction $\left(\Delta E_{\mathrm{rxn}}\right)$ of $-24.4 \mathrm{kcal} / \mathrm{mol}$ which are consistent with our previously published work. ${ }^{46,99}$

Table 11. Ab Initio QM/MM Results for the Water ... Sodium Complex; for all Calculations the Classical Portion Employed the TIP4PEW Water Model.

\begin{tabular}{|c|c|c|c|c|}
\hline Method & Basis set & $\Delta E$ & $d\left(\mathrm{O} \cdots \mathrm{Na}^{+}\right)$ & $\angle \mathrm{HO} \cdots \mathrm{Na}^{+}$ \\
\hline $\mathrm{HF}$ & cc-pVTZ & 27.812 & 2.096 & 127.7 \\
\hline $\mathrm{HF}$ & $6-311++\mathrm{G}(3 \mathrm{df}, 3 \mathrm{pd})$ & 27.904 & 2.094 & 127.8 \\
\hline B3LYP & cc-pVTZ & 27.832 & 2.095 & 127.8 \\
\hline B3LYP & $6-311++\mathrm{G}(3 \mathrm{df}, 3 \mathrm{pd})$ & 27.932 & 2.093 & 127.8 \\
\hline MP2 & cc-pVTZ & 27.796 & 2.095 & 127.7 \\
\hline MP2 & $6-311++\mathrm{G}(3 \mathrm{df}, 3 \mathrm{pd})$ & 27.895 & 2.094 & 127.7 \\
\hline CCSD & cc-pVTZ & 27.797 & 2.095 & 127.8 \\
\hline CCSD & $6-311++\mathrm{G}(3 \mathrm{df}, 3 \mathrm{pd})$ & 27.894 & 2.094 & 127.8 \\
\hline LDA-MM $^{17}$ & $6-31 G^{*}$ & 28.08 & 2.190 & 130.1 \\
\hline BLYP-MM $^{17}$ & $6-31 G^{*}$ & 28.07 & 2.190 & 130.1 \\
\hline $\operatorname{CCSD}(T)^{83}$ & cc-pCVTZ & 23.6 & 2.226 & \\
\hline Experimental $^{84}$ & & 24.0 & & \\
\hline
\end{tabular}

Binding energies, $\Delta E$, are reported in $\mathrm{kcal} / \mathrm{mol}$. Geometric parameters are reported in angstroms (bond distances) and degrees (bond angles). 
Table 12. Ab Initio QM/MM Results for the Water ... Sodium Complex; for all Calculations the Classical Portion Employed the TIP3P Water Model.

\begin{tabular}{lllll}
\hline Method & \multicolumn{1}{c}{ Basis set } & $\Delta E$ & $d\left(\mathrm{O} \cdots \mathrm{Na}^{+}\right)$ & $\angle \mathrm{HO} \cdots \mathrm{Na}^{+}$ \\
\hline HF & cc-pVTZ & 26.786 & 2.215 & 130.1 \\
HF & 6-311++G(3df,3pd) & 26.847 & 2.214 & 130.1 \\
B3LYP & cc-pVTZ & 26.775 & 2.216 & 130.1 \\
B3LYP & 6-311++G(3df,3pd) & 26.872 & 2.213 & 130.1 \\
MP2 & cc-pVTZ & 26.777 & 2.214 & 130.1 \\
MP2 & 6-311++G(3df,3pd) & 26.833 & 2.213 & 130.1 \\
CCSD & cc-pVTZ & 26.746 & 2.215 & 130.1 \\
CCSD & 6-311++G(3df,3pd) & 26.832 & 2.213 & 130.1 \\
LDA-MM ${ }^{17}$ & 6-31G* & 28.08 & 2.190 & 130.1 \\
BLYP-MM & 6-31G* & 28.07 & 2.190 & 130.1 \\
CCSD(T) & cc-pCVTZ & 23.6 & 2.226 & \\
Experimental $^{84}$ & & 24.0 & & \\
\hline
\end{tabular}

Binding energies, $\Delta E$, are reported in $\mathrm{kcal} / \mathrm{mol}$. Geometric parameters are reported in angstroms (bond distances) and degrees (bond angles).

However, $\Delta E^{\ddagger}$ and $\Delta E_{\mathrm{rxn}}$ computed at levels of theory that include electron correlation are drastically different. At the B3LYP/6$31+\mathrm{G}(\mathrm{d})$ and (RI)MP2/6-31+G(d) levels of theory, the barrier heights of this reaction are lowered by nearly $20 \mathrm{kcal} / \mathrm{mol}(8.95$ and 8.20 respectively, Table 17) which are in agreement with previously published by QM/MM studies. ${ }^{26,107-111}$ In addition, the geometrical parameters at the TSA are shifted away from those obtained with noncorrelated QM levels of theory (Table 18). It should be noted that increasing the level of QM theory (i.e., including electron correlation) had only a minor effect on $\Delta E_{\mathrm{rxn}}$, while the barrier regions (e.g., TSA), which are typically far more strained and/or diffuse in nature were significantly affected by the inclusion of correlation. We believe that our energy of reaction results are an improvement over previously published work (Table 18). ${ }^{107,108}$ This is due to the improved handling (via the replica path method) of the product (prephenate) state which Ranaghan et al. state to be problematic.

Given the fact that DFT is known to behave erratically for the prediction of barrier heights, we feel that this is a good test case for benchmarking the behavior of QM methods within a QM/MM framework. Of particular note in this example is the use of MP2 methods to treat the QM region. In recent work, researchers have found the use of QM/MM at the full MP2 level to be too time consuming to be practical. ${ }^{107}$ We show here that by employing QChem with CHARMM, not only can full MP2 be practical, but the use of RIMP2 (approximately half the cost of MP2) also yields nearly identical results.

Table 13. Ab Initio QM/MM Results for the Water ... Sodium Complex; for all Calculations the Classical Portion Employed the Polarizable Drude Water Model.

\begin{tabular}{lllcc}
\hline Method & \multicolumn{1}{c}{ Basis set } & $\Delta E$ & $d\left(\mathrm{O} \cdots \mathrm{Na}^{+}\right)$ & $\angle \mathrm{HO} \cdots \mathrm{Na}^{+}$ \\
\hline HF & cc-pVTZ & 29.468 & 2.258 & 127.7 \\
HF & 6-311++G(3df,3pd) & 29.643 & 2.256 & 127.7 \\
B3LYP & cc-pVTZ & 29.505 & 2.257 & 127.7 \\
B3LYP & 6-311++G(3df,3pd) & 29.694 & 2.558 & 127.7 \\
MP2 & cc-pVTZ & 29.491 & 2.258 & 127.7 \\
MP2 & 6-311++G(3df,3pd) & 29.675 & 2.255 & 127.7 \\
CCSD & cc-pVTZ & 29.469 & 2.258 & 127.7 \\
CCSD & 6-311++G(3df,3pd) & 29.643 & 2.256 & 127.7 \\
LDA-MM ${ }^{17}$ & 6-31G* & 28.08 & 2.190 & 130.1 \\
BLYP-MM & 6-31G* & 28.07 & 2.190 & 130.1 \\
CCSD(T) & cc-pCVTZ & 23.6 & 2.226 & \\
Experimental $^{84}$ & & 24.0 & & \\
\hline
\end{tabular}

Binding energies, $\Delta E$, are reported in $\mathrm{kcal} / \mathrm{mol}$. Geometric parameters are reported in angstroms (bond distances) and degrees (bond angles). 
Table 14. Ab Initio QM/MM Results for the Water . . Sodium Complex; for all Calculations the Classical Portion Employed the Recently Updated CHARMM Sodium Parameters (i.e., QM Water).

\begin{tabular}{llccc}
\hline Method & \multicolumn{1}{c}{ Basis set } & $\Delta E$ & $d\left(\mathrm{O} \cdots \mathrm{Na}^{+}\right)$ & $\angle \mathrm{HO} \cdots \mathrm{Na}^{+}$ \\
\hline HF & cc-pVTZ & 27.005 & 2.194 & 126.6 \\
HF & aug-cc-pVTZ & 29.594 & 2.159 & 124.8 \\
B3LYP & cc-pVTZ & 26.324 & 2.195 & 127.2 \\
B3LYP & aug-cc-pVTZ & 29.693 & 2.145 & 118.4 \\
MP2 & cc-pVTZ & 26.119 & 2.198 & 127.4 \\
MP2 & aug-cc-pVTZ & 29.412 & 2.146 & 117.1 \\
CCSD & cc-pVTZ & 26.023 & 2.198 & 127.3 \\
CCSD & aug-cc-pVTZ & 29.162 & 2.148 & 118.4 \\
LDA-MM ${ }^{17}$ & 6-31G* & 29.70 & 2.156 & 127.7 \\
BLYP-MM & 6-31G* & 28.24 & 2.163 & 128.1 \\
CCSD $(T)^{83}$ & cc-pCVTZ & 23.6 & 2.226 & \\
Experimental $^{84}$ & & 24.0 & & \\
\hline
\end{tabular}

Binding energies, $\Delta E$, are reported in $\mathrm{kcal} / \mathrm{mol}$. Geometric parameters are reported in angstroms (bond distances) and degrees (bond angles).

\section{Timings}

One of the fundamental reasons for employing the QM/MM methodology is its ability to treat large biologically relevant systems at a level of theory that is both accurate and affordable. The chorismate

Table 15. Full Ab Initio and QM/MM Replica Path Results for the Torsional Potential of Butane.

\begin{tabular}{lcccccc}
\hline Method & Basis set & $\Delta E_{1}^{\ddagger}$ & $\Delta E_{1}$ & $\Delta E_{2}^{\ddagger}$ & $\Delta E_{2}$ & $\Delta E_{3}^{\ddagger}$ \\
\hline
\end{tabular}

Full QM transition state optimization

\begin{tabular}{|c|c|c|c|c|c|c|}
\hline $\mathrm{HF}$ & $6-311+\mathrm{G}^{* *}$ & 3.63 & 0.96 & 6.32 & 0.96 & 3.63 \\
\hline B3LYP & $6-311+\mathrm{G}^{* *}$ & 3.13 & 0.76 & 5.68 & 0.76 & 3.13 \\
\hline MP2 & $6-311+\mathrm{G}^{* *}$ & 3.33 & 0.51 & 5.98 & 0.51 & 3.33 \\
\hline & \multicolumn{6}{|c|}{ Full QM replica path } \\
\hline $\mathrm{HF}$ & $6-311+\mathrm{G}^{* *}$ & 3.61 & 0.98 & 5.94 & 0.98 & 3.61 \\
\hline B3LYP & $6-311+\mathrm{G}^{* *}$ & 3.21 & 0.83 & 5.42 & 0.85 & 3.22 \\
\hline \multirow[t]{2}{*}{ MP2 } & $6-311+\mathrm{G}^{* *}$ & 3.29 & 0.53 & 5.48 & 0.53 & 3.2 \\
\hline & \multicolumn{6}{|c|}{ QM/MM replica path with SLA } \\
\hline $\mathrm{HF}$ & $6-311+\mathrm{G}^{* *}$ & 3.36 & 0.39 & 4.14 & 0.39 & 2.2 \\
\hline B3LYP & $6-311+\mathrm{G}^{* *}$ & 3.35 & 0.38 & 4.27 & 0.41 & 3.3 \\
\hline MP2 & $6-311+\mathrm{G}^{* *}$ & 3.35 & 0.39 & 4.12 & 0.39 & 3.3 \\
\hline \multirow[t]{2}{*}{ CCSD } & $6-311+\mathrm{G}^{* *}$ & 3.35 & 0.39 & 4.12 & 0.39 & 3.3 \\
\hline & \multicolumn{6}{|c|}{ QM/MM replica path with SLA and EXGR } \\
\hline $\mathrm{HF}$ & $6-311+\mathrm{G}^{* *}$ & 3.36 & 0.27 & 3.90 & 0.27 & 3.3 \\
\hline B3LYP & $6-311+\mathrm{G}^{* *}$ & 3.38 & 0.27 & 4.03 & 0.27 & 3. \\
\hline MP2 & $6-311+\mathrm{G}^{* *}$ & 3.35 & 0.24 & 3.86 & 0.24 & 3. \\
\hline CCSD & $6-311+\mathrm{G}^{* *}$ & 3.35 & 0.25 & 3.87 & 0.24 & \\
\hline $\mathrm{HF}^{13}$ & $6-31 G(d)$ & 3.4 & 0.4 & 4.7 & & \\
\hline Focal point ${ }^{89}$ & & 3.31 & 0.62 & 5.40 & & \\
\hline
\end{tabular}

Link atom treatments included SLA, EXGR, and DLA/DGMM (Ref. 13). Binding energies, $\Delta E$, and barrier heights, $\Delta E^{\ddagger}$, are reported in $\mathrm{kcal} / \mathrm{mol}$.

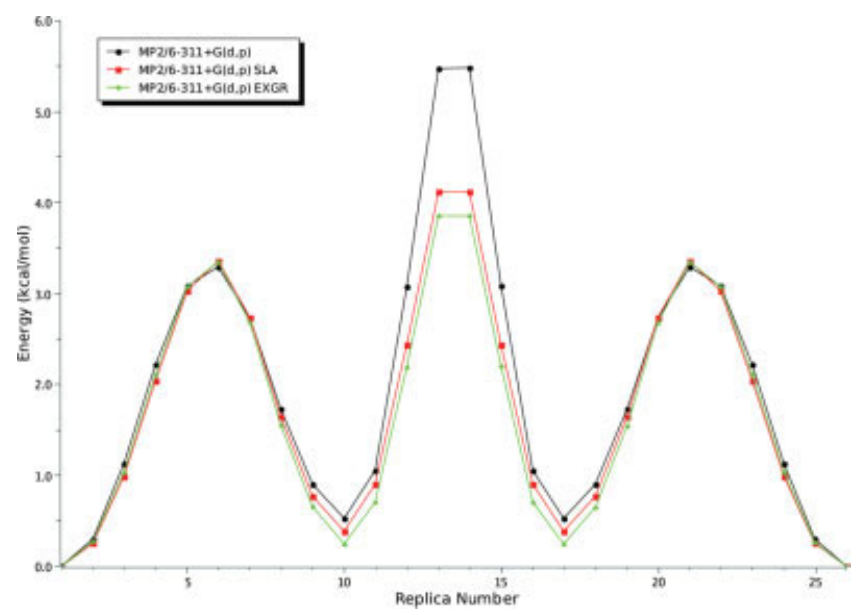

Figure 6. Full $\mathrm{QM}$ and $\mathrm{QM} / \mathrm{MM}$ results for the butane torsional potential. QM/MM link atom treatments employed the SLA and EXGR methods. All QM and QM/MM calculations were run at the MP2/6-311+G(d,p) level of theory with energies reported in $\mathrm{kcal} / \mathrm{mol}$. [Color figure can be viewed in the online issue, which is available at www.interscience.wiley.com.]

mutase enzymatic system was treated at four QM/MM levels of theory (HF/MM, B3LYP/MM, RIMP2/MM, MP2/MM), with the QM region consisting of 24 atoms, while the entire system had 14,516 atoms. All calculations were performed on dual processor $3.06 \mathrm{GHz}$ Xeon workstations with $2.0 \mathrm{~GB}$ of physical memory. The execution time (CPU) for a single energy and gradient evaluation (using QChem's default convergence and threshold criteria, employing the $6-31+\mathrm{G}^{*}$ basis set and running on a single processor) are as follows: HF/MM (21.0 min), B3LYP/MM (25.3 min), RIMP2/MM (41.4 min), and MP2/MM (81.0 min). Using Q-Chem's parallel HF and DFT routines can reduce these times significantly. For example,

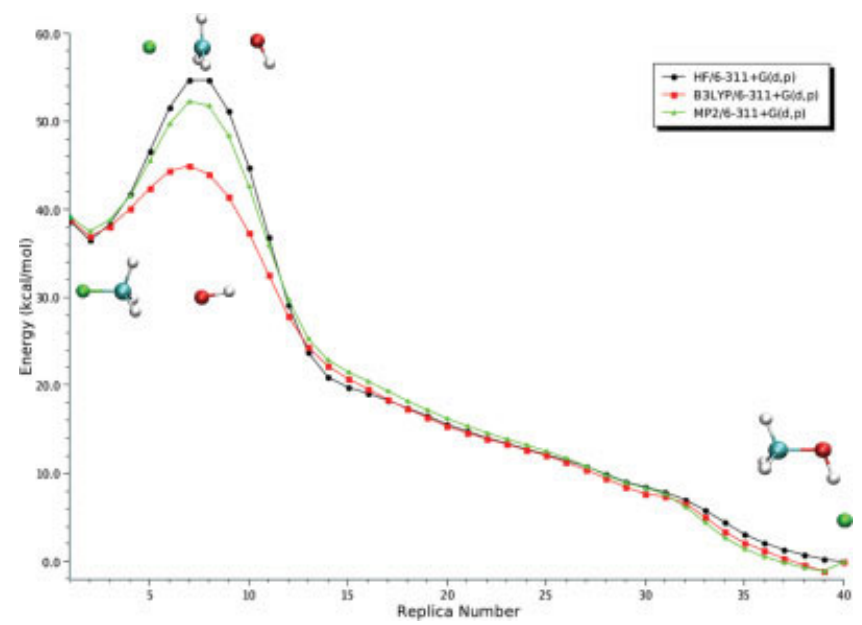

Figure 7. $\mathrm{OH}^{-}+\mathrm{CH}_{3} \mathrm{~F} \rightarrow \mathrm{CH}_{3} \mathrm{OH}+\mathrm{F}^{-}$reaction profile computed at the replica path $\mathrm{HF} / 6-311+\mathrm{G}(\mathrm{d}, \mathrm{p}), \mathrm{B} 3 \mathrm{LYP} / 6-311+\mathrm{G}(\mathrm{d}, \mathrm{p})$, and MP2/6-311+G(d,p) levels of theory with energies reported in $\mathrm{kcal} / \mathrm{mol}$. [Color figure can be viewed in the online issue, which is available at www.interscience.wiley.com.] 
Table 16. Full Ab Initio Replica Path Results For the $\mathrm{OH}^{-}+\mathrm{CH}_{3} \mathrm{~F} \rightarrow \mathrm{CH}_{3} \mathrm{OH}+\mathrm{F}^{-}$reaction.

\begin{tabular}{|c|c|c|c|c|}
\hline Method & Basis set & $\Delta E^{\ddagger}($ Forward $)$ & $\Delta E^{\ddagger}($ Reverse $)$ & $\Delta E_{\mathrm{rXn}}$ \\
\hline $\mathrm{HF}^{\mathrm{a}}$ & $6-311+\mathrm{G}^{* *}$ & 18.28 & 54.74 & 36.46 \\
\hline B3LYPa & $6-311+\mathrm{G}^{* *}$ & 8.02 & 46.10 & 38.08 \\
\hline $\mathrm{MP}^{\mathrm{a}}$ & $6-311+\mathrm{G}^{* *}$ & 14.75 & 53.44 & 38.69 \\
\hline MP2 $2^{96}$ & $6-311++\mathrm{G}^{* *}$ & 12.89 & 51.18 & 38.29 \\
\hline $\mathrm{HF}^{97,98}$ & $\mathrm{DZP}+$ diffuse & 19.13 & 54.84 & 35.71 \\
\hline $\mathrm{HF}^{97,98}$ & $\mathrm{TZ2P}+$ diffuse & 17.68 & 52.75 & 35.07 \\
\hline $\mathrm{HF}^{97,98}$ & TZ2Pf + diffuse & 18.80 & 53.64 & 34.84 \\
\hline MP2 $2^{97,98}$ & $\mathrm{DZP}+$ diffuse & 12.62 & 50.35 & 37.73 \\
\hline MP2 $2^{97,98}$ & TZ2P + diffuse & 9.88 & 45.77 & 35.89 \\
\hline MP $2^{97,98}$ & TZ2Pf + diffuse & 11.37 & 48.20 & 36.83 \\
\hline B3LYP 95 & MG3S & 7.37 & 45.05 & 37.68 \\
\hline $\mathrm{O}^{2} \mathrm{LYP}^{95}$ & MG3S & 7.73 & 46.57 & 38.84 \\
\hline MPW1K ${ }^{95}$ & MG3S & 11.42 & 51.82 & 40.40 \\
\hline BLYP $^{95}$ & MG3S & 3.20 & 39.80 & 36.60 \\
\hline Focal point ${ }^{97,98}$ & & 11.20 & 46.67 & 35.47 \\
\hline
\end{tabular}

Barrier heights, $\Delta E^{\ddagger}$, and reactions energies, $\Delta E_{\mathrm{rxn}}$, are reported in $\mathrm{kcal} / \mathrm{mol}$.

${ }^{\text {a }}$ Current work.

Table 17. QM/MM Optimized Geometric Parameters for the Chorismate Mutase Catalyzed Claisen

Rearrangement.

\begin{tabular}{|c|c|c|c|c|c|c|c|c|c|c|c|}
\hline $\begin{array}{l}\text { Geometric } \\
\text { Parameter }\end{array}$ & $\begin{array}{c}\mathrm{HF} / \\
4-31 \mathrm{G}\end{array}$ & $\begin{array}{c}\mathrm{HF} / \\
6-31 \mathrm{G}(\mathrm{d})\end{array}$ & $\begin{array}{c}\mathrm{HF} / \\
6-31+\mathrm{G}(\mathrm{d})\end{array}$ & $\begin{array}{l}\text { B3LYP/ } \\
6-31 G(d)\end{array}$ & $\begin{array}{c}\text { B3LYP/ } \\
6-31+\mathrm{G}(\mathrm{d})\end{array}$ & $\begin{array}{l}\text { RIMP2/ } \\
\text { 6-31G(d) }\end{array}$ & $\begin{array}{c}\text { RIMP2/ } \\
6-31+G(d)\end{array}$ & $\begin{array}{c}\text { MP2/ } \\
6-31 \mathrm{G}(\mathrm{d})\end{array}$ & $\begin{array}{c}\text { MP2/ } \\
6-31+G(d)\end{array}$ & $\begin{array}{c}\text { Lee } \\
\text { et al. }{ }^{99, \mathrm{a}}\end{array}$ & $\begin{array}{l}\text { Ranaghan } \\
\text { et al. }{ }^{107, b}\end{array}$ \\
\hline \multicolumn{12}{|c|}{ Chorismate } \\
\hline $\mathrm{C} 1-\mathrm{C} 9$ & 3.14 & 3.18 & 3.21 & 3.11 & 3.13 & 2.96 & 3.01 & 2.96 & 3.01 & 3.28 & 3.44 \\
\hline $\mathrm{C} 3-\mathrm{O} 7$ & 1.50 & 1.46 & 1.47 & 1.51 & 1.51 & 1.51 & 1.52 & 1.51 & 1.52 & 1.49 & 1.45 \\
\hline O13-R7(HH12) & 1.72 & 1.73 & 1.76 & 1.76 & 1.79 & 1.75 & 1.78 & 1.75 & 1.78 & 1.77 & 1.70 \\
\hline O7-R90(HE) & 2.40 & 2.33 & 2.34 & 2.30 & 2.31 & 2.30 & 2.29 & 2.29 & 2.29 & 2.06 & 2.68 \\
\hline O7-R90(HH21) & 1.68 & 1.77 & 1.79 & 1.82 & 1.85 & 1.81 & 1.85 & 1.81 & 1.85 & 1.69 & 1.96 \\
\hline O14-R90(HE) & 1.78 & 1.84 & 1.86 & 1.89 & 1.92 & 1.89 & 1.93 & 1.89 & 1.93 & 1.95 & 1.65 \\
\hline O12-C75(HG1) & 2.32 & 2.36 & 2.35 & 2.40 & 2.37 & 2.36 & 2.33 & 2.36 & 2.33 & 2.46 & 2.86 \\
\hline $\mathrm{O} 12-\mathrm{C} 75(\mathrm{SG})$ & 3.50 & 3.52 & 3.51 & 3.55 & 3.52 & 2.51 & 3.49 & 3.51 & 3.49 & 3.45 & 3.61 \\
\hline \multicolumn{12}{|c|}{ Transition state analog (TSA) } \\
\hline $\mathrm{C} 1-\mathrm{C} 9$ & 2.44 & 2.57 & 2.68 & 2.63 & 2.72 & 2.36 & 2.41 & 2.35 & 2.41 & 2.50 & 2.58 \\
\hline $\mathrm{C} 3-\mathrm{O} 7$ & 2.23 & 2.20 & 2.28 & 2.09 & 2.13 & 1.89 & 1.92 & 1.89 & 1.92 & 2.30 & 2.28 \\
\hline O13-R7(HH12) & 1.69 & 1.70 & 1.72 & 1.75 & 1.76 & 1.75 & 1.77 & 1.75 & 1.77 & 1.75 & 1.66 \\
\hline O7一R90(HE) & 2.21 & 2.10 & 2.04 & 2.12 & 2.13 & 2.22 & 2.22 & 2.22 & 2.22 & 2.01 & 2.65 \\
\hline $\mathrm{O} 7-\mathrm{R} 90(\mathrm{HH} 21)$ & 1.68 & 1.74 & 1.76 & 1.79 & 1.83 & 1.82 & 1.86 & 1.81 & 1.86 & 1.64 & 1.77 \\
\hline O14—R90(HE) & 1.91 & 1.98 & 2.06 & 2.01 & 2.04 & 1.95 & 1.98 & 1.95 & 1.98 & 1.99 & 1.69 \\
\hline $\mathrm{O} 12-\mathrm{C} 75(\mathrm{HG} 1)$ & 2.43 & 2.44 & 2.44 & 2.43 & 2.40 & 2.41 & 2.37 & 2.40 & 2.37 & 2.62 & 3.09 \\
\hline $\mathrm{O} 12-\mathrm{C} 75(\mathrm{SG})$ & 3.57 & 3.57 & 3.57 & 3.57 & 3.54 & 3.36 & 3.52 & 3.55 & 3.52 & 3.55 & 2.68 \\
\hline$\delta=\mathrm{d}_{\mathrm{C} 1}-\mathrm{C} 9-\mathrm{d}_{\mathrm{C} 3}-\mathrm{O} 7$ & 0.21 & 0.37 & 0.40 & 0.53 & 0.59 & 0.46 & 0.49 & 0.46 & 0.49 & 0.20 & 0.30 \\
\hline \multicolumn{12}{|c|}{ Prephenate } \\
\hline $\mathrm{C} 1-\mathrm{C} 9$ & 1.58 & 1.57 & 1.58 & 1.59 & 1.60 & 1.58 & 1.58 & 1.57 & 1.58 & 1.49 & 1.78 \\
\hline $\mathrm{C} 3-\mathrm{O} 7$ & 3.36 & 3.39 & 3.43 & 3.29 & 3.33 & 3.20 & 3.24 & 3.20 & 3.24 & 3.28 & 3.38 \\
\hline O13-R7(HH12) & 1.74 & 1.76 & 1.77 & 1.79 & 1.81 & 1.79 & 1.81 & 1.79 & 1.81 & 1.77 & 1.69 \\
\hline O7-R90(HE) & 2.09 & 2.00 & 2.02 & 1.98 & 2.04 & 2.00 & 2.04 & 2.00 & 2.04 & 2.28 & 2.82 \\
\hline O7-R90(HH21) & 1.77 & 1.85 & 1.88 & 1.88 & 1.91 & 1.89 & 1.92 & 1.89 & 1.92 & 1.68 & 1.83 \\
\hline O14-R90(HE) & 2.09 & 2.18 & 2.18 & 2.22 & 2.20 & 2.18 & 2.18 & 2.18 & 2.18 & 1.92 & 1.69 \\
\hline $\mathrm{O} 12-\mathrm{C} 75(\mathrm{HG} 1)$ & 2.66 & 2.67 & 2.69 & 2.71 & 2.72 & 2.72 & 2.71 & 2.72 & 2.71 & 2.74 & 2.78 \\
\hline $\mathrm{O} 12-\mathrm{C} 75(\mathrm{SG})$ & 3.74 & 3.74 & 3.76 & 3.77 & 3.77 & 3.78 & 3.78 & 3.78 & 3.78 & 3.64 & 3.82 \\
\hline
\end{tabular}

All bond distances are reported in Angstroms $(\AA)$.

${ }^{a}$ Lee et al. ${ }^{99}$ pathway was optimized at the HF/4-31G level of QM theory.

${ }^{b}$ Ranaghan et al. ${ }^{107}$ pathway was optimized at the HF/6-31G(d) level of QM theory. 


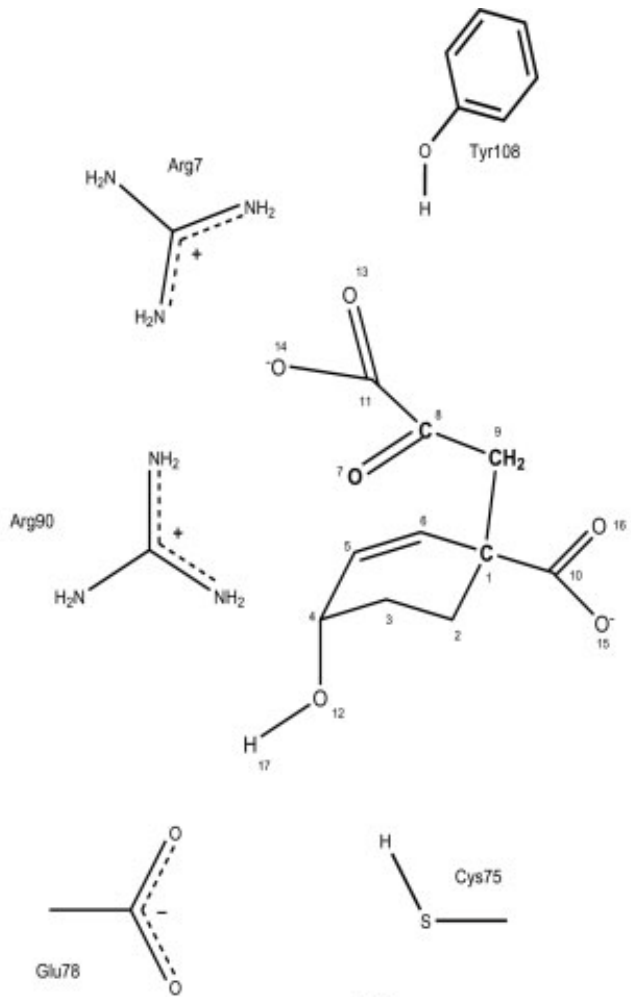

(a)
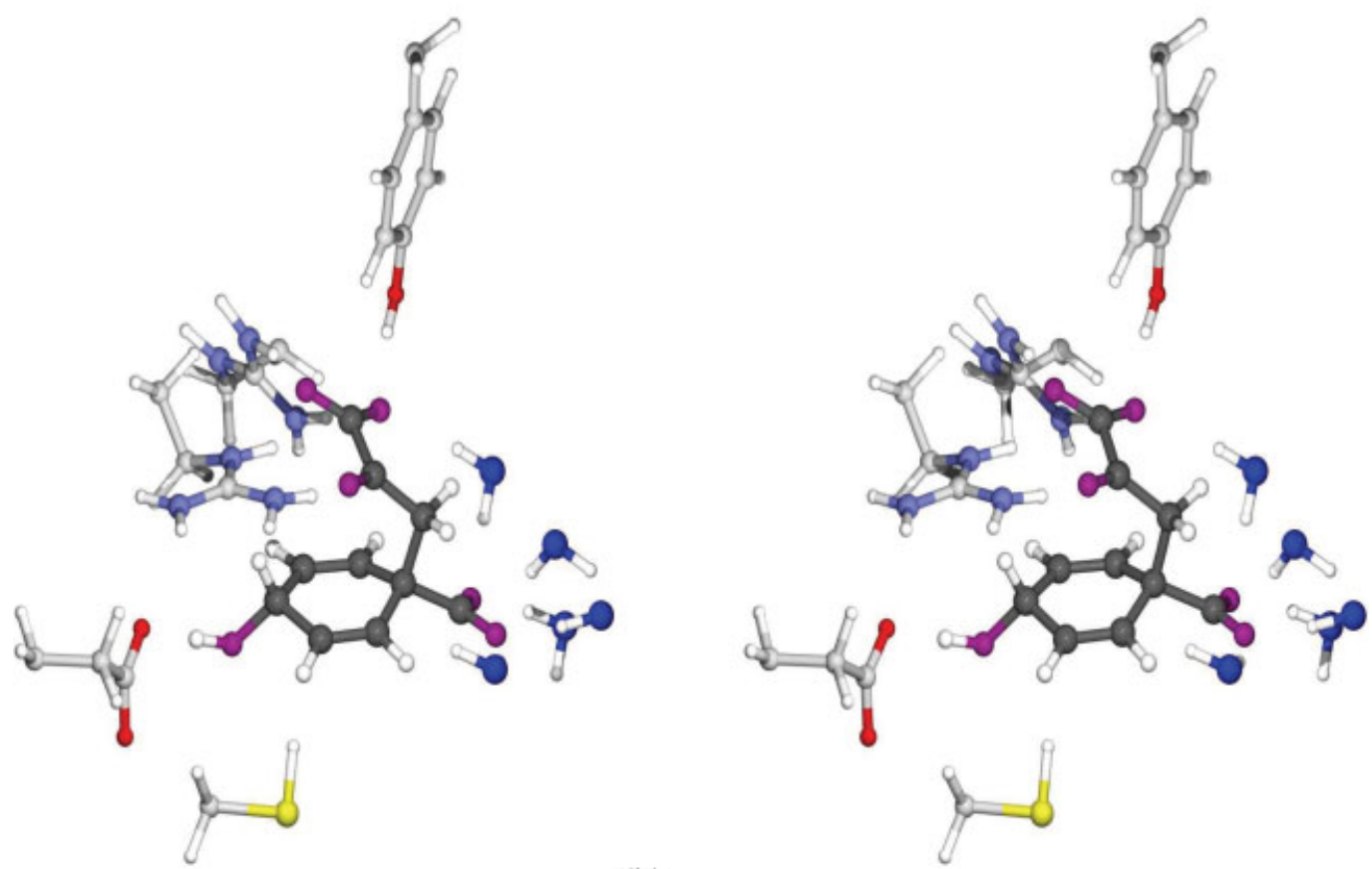

(b)

Figure 8. (a) Model of the chorismate mutase active site with interacting residues shown. (b) Stereo view of the chorismate mutase active site with interacting residues shown. 
Table 18. QM/MM Reaction $\left(\Delta E_{\mathrm{rxn}}\right)$ and Activation $\left(\Delta E^{\ddagger}\right)$ Energy for the Chorismate Mutase Catalyzed Claisen Rearrangement.

\begin{tabular}{|c|c|c|}
\hline Level of Theory & $\Delta E_{\mathrm{rxn}}$ & $\Delta E^{\ddagger}$ \\
\hline HF/6-31G(d)/CHARMM22 ${ }^{107}$ & & 36.6 \\
\hline MP2/6-31+G(d)//HF/6-31G(d)/CHARMM22 $2^{107}$ & -35.6 & 11.0 \\
\hline B3LYP/6-31+G(d)//HF/6-31G(d)/CHARMM22 $2^{107}$ & -30.9 & 16.1 \\
\hline MP2/6-31+G(d) + AM1/CHARMM22 $2^{107}$ & -30.7 & 12.3 \\
\hline B3LYP/6-311+G(2d,p) + AM1/CHARMM22 107 & -26.1 & 15.2 \\
\hline PBE/DVZP/Amber ${ }^{\mathrm{a}, 26}$ & -24.9 & 5.3 \\
\hline PBE/DVZP/Amber ${ }^{\mathrm{b}, 26}$ & -30.6 & 4.3 \\
\hline HF/4-31G/CHARMM22 ${ }^{99}$ & -20.1 & 20.1 \\
\hline Replica Path HF/4-31G/CHARMM22 $2^{46}$ & -15.3 & 33.4 \\
\hline \multicolumn{3}{|l|}{ Replica Path B3LYP/6-31G(d)// } \\
\hline HF/4-31G/CHARMM22 ${ }^{46}$ & -19.5 & 14.9 \\
\hline HF/4-31G/CHARMM $22^{c}$ & -16.3 & 26.2 \\
\hline $\mathrm{HF} / 6-31 \mathrm{G}(\mathrm{d}) / \mathrm{CHARMM} 22^{\mathrm{c}}$ & -25.7 & 27.2 \\
\hline $\mathrm{HF} / 6-31+\mathrm{G}(\mathrm{d}) / \mathrm{CHARMM} 22^{\mathrm{c}}$ & -24.4 & 26.2 \\
\hline B3LYP/6-31G(d)/CHARMM $22^{c}$ & -21.2 & 9.63 \\
\hline B3LYP/6-31+G(d)/CHARMM $22^{c}$ & -19.5 & 8.95 \\
\hline RIMP2/6-31G(d)/CHARMM $22^{c}$ & -25.9 & 8.64 \\
\hline RIMP2/6-31+G(d)/CHARMM22 ${ }^{c}$ & -23.1 & 8.18 \\
\hline MP2/6-31G(d)/CHARMM $22^{\mathrm{c}}$ & -25.8 & 8.69 \\
\hline MP2/6-31+G(d)/CHARMM22 ${ }^{\mathrm{c}}$ & -23.1 & 8.20 \\
\hline $\operatorname{Experimental}(\Delta \mathrm{H})^{102}$ & & $12.7 \pm 0.4$ \\
\hline
\end{tabular}

All energies are reported in $\mathrm{kcal} / \mathrm{mol}$.

${ }^{\mathrm{a}}$ Only substrate included in QM region (24 Atoms).

${ }^{\mathrm{b}}$ Substrate + Glu78 and Arg90 included in QM region.

${ }^{\mathrm{c}}$ This work.

$\mathrm{HF} / \mathrm{MM}$ and B3LYP/MM calculations run on 8 processors (4 dual nodes with gigabit ethernet connectivity) took only 3.6 and 4.1 $\mathrm{min}$, respectively. Another interesting aspect to examine is the time required to do the QM part of the calculation versus the QM/MM part. On running just the 24 atom QM region, we get the following timings at the HF (8.73 min), B3LYP (11.6 min), RIMP2 (27.2 $\mathrm{min}$ ), and MP2 (59.1 min) level of theory again with the $6-31+\mathrm{G}(\mathrm{d})$. This is interesting as in some cases more than half of the CPU time is spent computing the QM/MM interactions which suggests that efficiency improvements in this part of the calculation could yield significant benefits with respect to the total computational cost.

\section{Conclusions}

A hybrid QM/MM potential has been implemented between CHARMM and Q-Chem highlighting new parallel/parallel methods for studying reaction pathways. Our new QM/MM interface follows closely to those previously developed, with the exception that it uses external data sharing rather than enforcing the requirement of joint compilation. The new interface completely supports both the parallel/parallel replica path method and nudged elastic band methods as implemented in CHARMM. Both SLA and EXGR link atom methods are supported. The new interface supports HF, DFT, RIMP2, MP2, and CCSD QM/MM minimizations and can be extended to support excited state methods (i.e., spin-flip methods). ${ }^{112-114}$
To confirm our implementation, we evaluated several test cases. In particular, the use of the new Drude polarizable water model in QM/MM calculations presents an interesting opportunity to better describe solvent-solute interactions with QM/MM potentials. We have shown that this approach is not only available but can also yield better results than the use of TIP3P waters in QM/MM solvation studies. The example we point to here is that the use of the Drude water model yielded the correct symmetry for the chloride-water complex, whereas both TIP3P and TIP4PEW were unable to find the global $\mathrm{C}_{s}$ minimum.

We examined a gas-phase $S_{N} 2$ reaction to illustrate the usefullness of replica methods and demonstrate the functionality of our parallel/parallel interface. Our results were in excellent agreement with previously published high level QM studies of the $\mathrm{OH}^{-}+\mathrm{CH}_{3} \mathrm{~F} \rightarrow \mathrm{CH}_{3} \mathrm{OH}+\mathrm{F}^{-}$reaction. We also note that care must be taken when choosing a QM method for studying reaction paths as the correct description of dispersion plays a key role in accurate barrier height predictions. Using our QM/MM interface, post-HF pathway (i.e., MP2, RIMP2, CCSD) optimizations can easily be carried out to avoid this problem.

We employed the replica path method in conjunction with distance restraints to characterize the reaction profile of the chorismate mutase catalyzed Claisen rearrangement. We computed both $\Delta E^{\ddagger}$ and $\Delta E_{\mathrm{rxn}}$ at various QM/MM levels of theory and found that the inclusion of electron correlation (DFT, RIMP2, MP2) gives significantly different results than non-correlated (HF) methods. From our results it is clear that the level of QM theory used in QM/MM calculations has a large effect on the results of transition state geometries and barrier heights. When examining a reaction path where the accurate description of diffuse and/or strained transition state analog(s) is of vital importance, the use of correlated QM methods may be essential.

\section{Acknowledgments}

The authors acknowledge helpful discussions with Dr. Damian Moran, Dr. Joseph D. Larkin, Dr. Yihan Shao, Professor Martin Head-Gordon, Professor George Stan, and Dr. Paul Sherwood. The help of Rick Venable with CHARMM graphics is also greatly appreciated. The use of the LoBoS (http://www.lobos.nih.gov) and Biowulf (http://biowulf.nih.gov/) super computing systems is acknowledged and appreciated.

\section{References}

1. Head-Gordon, M. J Phys Chem 1996, 100, 13213.

2. Jung, Y.; Sodt, A.; Gill, P. M. W.; Head-Gordon, M. Proc Natl Acad Sci USA 2005, 102, 6692.

3. White, C. A.; Johnson, B. G.; Gill, P. M. W.; Head-Gordon, M. Chem Phys Lett 1994, 230, 8.

4. White, C. A.; Johnson, B. G.; Gill, P. M. W.; Head-Gordon, M. Chem Phys Lett 1996, 253, 268.

5. Strain, M. C.; Scuseria, G. E.; Frisch, M. J. Science 1996, $271,51$.

6. Lee, T. S.; Lewis, J. P.; Yang, W. T. Comput Mater Sci 1998, 12, 259.

7. Warshel, A.; Levitt, M. J Mol Biol 1976, 103, 227.

8. Singh, U. C.; Kollman, P. A. J Comput Chem 1986, 7, 718.

9. Field, M. J.; Bash, P. A.; Karplus, M. J Comput Chem 1990, 11, 700.

10. Car, R.; Parrinello, M. Phys Rev Lett 1985, 55, 2471. 
11. Svensson, M.; Humbel, S.; Froese, R. D. J.; Matsubara, T.; Sieber, S.; Morokuma, K. J Phys Chem 1996, 100, 19357.

12. Maseras, F.; Morokuma, K. J Comput Chem 1995, 16, 1170.

13. Das, D.; Eurenius, K. P.; Billings, E. M.; Sherwood, P.; Chatfield, D. C.; Hodoscek, M.; Brooks, B. R. J Chem Phys 2002, 117, 10534.

14. Pu, J. Z.; Gao, J. L.; Truhlar, D. G. J Phys Chem A 2004, 108, 632.

15. Philipp, D. M.; Friesner, R. A. J Comput Chem 1999, 20, 1468.

16. Zhang, Y. K.; Lee, T. S.; Yang, W. T. J Chem Phys 1999, $110,46$.

17. Lyne, P. D.; Hodoscek, M.; Karplus, M. J Phys Chem A 1999, 103, 3462 .

18. Loferer, M. J.; Loeffler, H. H.; Liedl, K. R. J Comput Chem 2003, 24, 1240

19. Woo, T. K.; Margl, P. M.; Blochl, P. E.; Ziegler, T. J Phys Chem B 1997, 101, 7877.

20. Cui, Q.; Elstner, M.; Kaxiras, E.; Frauenheim, T.; Karplus, M. J Phys Chem B 2001, 105, 569.

21. Sherwood, P.; de Vries, A. H.; Guest, M. F.; Schreckenbach, G.; French, S. A.; Sokol, A. A.; Bromley, S. T.; Thiel, W.; Turner, A. J. J Mol Struct (Theochem) 2003, 632, 1.

22. Mo, Y. R.; Gao, J. L. J Comput Chem 2000, 21, 1458.

23. Gao, J. L. J Am Chem Soc 1994, 116, 1563.

24. Stanton, R. V.; Hartsough, D. S.; Merz, K. M. J Phys Chem 1993, 97 , 11868.

25. Kairys, V.; Jensen, J. H. J Phys Chem A 2000, 104, 6656.

26. Crespo, A.; Scherlis, D. A.; Marti, M. A.; Ordejon, P.; Roitberg, A. E.; Estrin, D. A. J Phys Chem B 2003, 107, 13728.

27. Dewar, M. J. S.; Zoebisch, E. G.; Healy, E. F.; Stewart, J. J. P. J Am Chem Soc 1985, 107, 3902.

28. Stewart, J. P. J Comput Chem 1989, 10, 209.

29. Warshel, A. Computer Modeling of Chemical Reactions in Enzymes and Solutions, John Wiley: New York, 1991.

30. Hehre, W. J.; Radom, L.; Pople, J. A.; Schleyer, P. v. R. Ab Initio Molecular Orbital Theory, John Wiley: New York, 1986.

31. Yang, W.; Parr, R. G. Density Functional Theory of Atoms and Molecules; Oxford University Press: New York, 1989.

32. Laio, A.; VandeVondele, J.; Rothlisberger, U. J Chem Phys 2002, 116, 6941.

33. Eichinger, M.; Tavan, P.; Hutter, J.; Parrinello, M. J Chem Phys 1999, 110,10452

34. Murphy, R. B.; Philipp, D. M.; Friesner, R. A. Chem Phys Lett 2000, 321,113 .

35. Friesner, R. A. Proc Natl Acad Sci USA 2005, 102, 6648.

36. Thiel, W.; Voityuk, A. A. J Phys Chem 1996, 100, 616.

37. Luque, F. J.; Reuter, N.; Cartier, A.; Ruiz-Lopez, M. F. J Phys Chem A $2000,104,10923$

38. Shao, Y.; Fusti-Molnar, L.; Jung, Y.; Kussmann, J.; Ochsenfeld, C.; Brown, S. T.; Gilbert, A. T. B.; Slipchenko, L. V.; Levchenko, S. V.; O'Neill, D. P.; Distasio, R. A.; Lochan, R. C.; Wang, T.; Beran, G. J. O.; Besley, N. A.; Herbert, J. M.; Lin, C. Y.; Van Voorhis, T.; Chien, S. H.; Sodt, A.; Steele, R. P.; Rassolov, V. A.; Maslen, P. E.; Korambath, P. P.; Adamson, R. D.; Austin, B.; Baker, J.; Byrd, E. F. C.; Daschel, H.; Doerksen, R. J.; Dreuw, A.; Dunietz, B. D.; Dutoi, A. D.; Furlani, T. R.; Gwaltney, S. R.; Heyden, A.; Hirata, S.; Hsu, C. P.; Kedziora, G.; Khalliulin, R. Z.; Klunzinger, P.; Lee, A. M.; Lee, M. S.; Liang, W.; Lotan, I.; Nair, N.; Peters, B.; Proynov, E. I.; Pieniazek, P. A.; Rhee, Y. M.; Ritchie, J.; Rosta, E.; Sherrill, D. C.; Simmonett, A. C.; Subotnik, J. E.; Woodcock, H. L.; Zhang, W.; Bell, A. T.; Chakraborty, A. K.; Chipman, D. M.; Keil, F. J.; Warshel, A.; Hehre, W. J.; Schaefer, H. F.; Kong, J.; Krylov, A. I.; Gill, P. M. W.; Head-Gordon, M. Phys Chem Chem Phys 2006, 8, 3172.

39. Brooks, B. R.; Bruccoleri, R. E.; Olafson, B. D.; States, D. J.; Swaminathan, S.; Karplus, M. J Comput Chem 1983, 4, 187.

40. Gao, J. L.; Xia, X. F. Science 1992, 258, 631.

41. Gao, J. L. J Phys Chem 1992, 96, 537.
42. Gao, J. L. J Am Chem Soc 1994, 116, 9324.

43. Besley, N.; Oakley, M.; Cowan, A.; Hirst, J. J Am Chem Soc 2004, $126,13502$.

44. Liu, H.; Muller-Plathe, F.; van Gunsteren, W. F. J Chem Phys 1995, $102,1722$.

45. Lu, Z. Y.; Yang, W. T. J Chem Phys 2004, 121, 89.

46. Woodcock, H. L.; Hodoscek, M.; Sherwood, P.; Lee, Y. S.; Schaefer, H. F.; Brooks, B. R. Theor Chem Acc 2003, 109, 140.

47. Chu, J. W.; Trout, B. L.; Brooks, B. R. J Chem Phys 2003, 119, 12708.

48. Mills, G.; Jonsson, H.; Schenter, G. Surf Sci 1995, 324, 305.

49. Henkelman, G.; Jonsson, H. J Chem Phys 2000, 113, 9978.

50. Henkelman, G.; Uberuaga, B.; Jonsson, H. J Chem Phys 2000, 113, 9901.

51. Schmidt, M. W.; Baldridge, K. K.; Boatz, J. A.; Elbert, S. T.; Gordon, M. S.; Jensen, J. H.; Koseki, S.; Matsunaga, N.; Nguyen, K. A.; Su, S. J.; Windus, T. L.; Dupuis, M.; Montgomery, J. A. J Comput Chem 1993, 14, 1347.

52. Guest, M. F.; Bush, I. J.; Van Dam, H. J. J.; Sherwood, P.; Thomas, J. M. H.; Van Lenthe, J. H.; Havenith, R. W. A.; Kendrick, J. Mol Phys 2005, 103, 719.

53. Boresch, S.; Karplus, M. J Chem Phys A 1999, 103, 103.

54. Li, G. H.; Zhang, X. D.; Cui, Q. J Phys Chem B 2003, 107, 8643.

55. Gao, J. L. J Comp Chem 1997, 18, 1061.

56. Ziegler, T. Chem Rev 1991, 91, 651.

57. Lamoureux, G.; MacKerell, A. D.; Roux, B. J Chem Phys 2003, 119, 5185.

58. Woodcock, H. L.; current CHARMM version, qchem.doc, 2005 (http://www.charmm.org/document/chmdocs.shtml).

59. Ahlrichs, R.; Bar, M.; Haser, M.; Horn, H.; Kolmel, C. Chem Phys Lett $1989,162,165$.

60. Fukui, K. Acc Chem Res 1981, 14, 363.

61. Gonzalez, C.; Schlegel, H. B. J Phys Chem 1990, 94, 5523.

62. Gonzalez, C.; Schlegel, H. B. J Phys Chem 1989, 90, 2154.

63. Ayala, P. Y.; Schlegel, H. B. J Chem Phys 1997, 107, 375.

64. Czerminski, R.; Elber, R. J Chem Phys 1990, 92, 5580.

65. Czerminski, R.; Elber, R. Int J Quantum Chem 1990, 38, 167.

66. Elber, R.; Karplus, M. Chem Phys Lett 1987, 139, 375.

67. Cisneros, G.; Liu, H.; Lu, Z.; Yang, W. J Chem Phys 2005, 122(11), 114502-114508.

68. Xie, L.; Liu, H.; Yang, W. J Chem Phys 2004, 120, 8039.

69. Liu, H.; Lu, Z.; Cisneros, G.; Yang, W. J Chem Phys 2004, 121, 697.

70. Zhang, Y.; Liu, H.; Yang, W. J Chem Phys 2000, 112, 3483.

71. Roux, B.; Karplus, M. J Comput Chem 1995, 16, 690.

72. MacKerell, A. D.; Bashford, D.; Bellott, M.; Dunbrack, R. L.; Evanseck, J. D.; Field, M. J.; Fischer, S.; Gao, J.; Guo, H.; Ha, S.; Joseph-McCarthy, D.; Kuchnir, L.; Kuczera, K.; Lau, F. T. K.; Mattos, C.; Michnick, S.; Ngo, T.; Nguyen, D. T.; Prodhom, B.; Reiher, W. E.; Roux, B.; Schlenkrich, M.; Smith, J. C.; Stote, R.; Straub, J.; Watanabe, M.; Wiorkiewicz-Kuczera, J.; Yin, D.; Karplus, M. J Phys Chem B 1998, 102, 3586.

73. Lamoureux, G.; Roux, B. J Phys Chem B 2006, 110, 3308.

74. Klopper, W.; van Duijneveldt-van de Rijdt, J. G. C. M.; van Duijneveldt, F. B. Phys Chem Chem Phys 2000, 2, 2227.

75. Tschumper, G. S.; Leininger, M. L.; Hoffman, B. C.; Valeev, E. F.; Schaefer, H. F.; Quack, M. J Chem Phys 2002, 116, 690.

76. Curtiss, L. A.; Frurip, D. J.; Blander, M. J Chem Phys 1979, 71, 2703.

77. Reimers, J. R.; Watts, R. O.; Klein, M. L. Chem Phys 1982, 64, 95.

78. Jorgensen, W.; Chandrasekhar, J.; Madura, J.; Impey, R.; Klein, M. J Chem Phys 1983, 79, 926.

79. Durell, S. R.; Brooks, B. R.; Bennaim, A. J Phys Chem 1994, 98, 2198.

80. Horn, H. W.; Swope, W. C.; Pitera, J. W.; Madura, J. D.; Dick, T. J.; Hura, G. L.; Head-Gordon, T. J Chem Phys 2004, 120, 9665.

81. Xantheas, S. S. J Phys Chem 1996, 100, 9703. 
82. Yamdagni, R.; Kebarle, P. J Am Chem Soc 1971, 93, 7139.

83. Feller, D.; Glendening, E. D.; Woon, D. E.; Feyereisen, M. W. J Chem Phys 1995, 103, 3526.

84. Dzidic, I.; Kebarle, P. J Phys Chem 1970, 74, 1466.

85. Pitzer, K. S. J Chem Phys 1940, 8, 711.

86. Klauda, J. B.; Brooks, B. R.; MacKerell, A. D.; Venable, R. M.; Pastor, R. W. Biophys J 2005, 88, 148.

87. Klauda, J. B.; Brooks, B. R.; MacKerell, A. D.; Venable, R. M.; Pastor, R. W. J Phys Chem B 2005, 109, 5300.

88. Feller, S. E.; MacKerell, A. D. J Phys Chem B 2000, 104, 7510.

89. Allinger, N. L.; Fermann, J. T.; Allen, W. D.; Schaefer, H. F. J Chem Phys 1997, 106, 5143.

90. Vasilyev, V. V. J Mol Struct (Theochem) 1994, 110, 129.

91. Waszkowycz, B.; Hillier, I. H.; Gensmantel, N.; Payling, D. W. J Chem Soc Perkin Trans 2 1991, 2, 225.

92. Waszkowycz, B.; Hillier, I. H.; Gensmantel, N.; Payling, D. W. J Chem Soc Perkin Trans 2 1991, 11, 1819.

93. Waszkowycz, B.; Hillier, I. H.; Gensmantel, N.; Payling, D. W. J Chem Soc Perkin Trans 2 1991, 12, 2025.

94. Konig, P. H.; Hoffmann, M.; Frauenheim, T.; Cui, Q. J Phys Chem B 2005, 109, 9082.

95. Zhao, Y.; Gonzalez-Garcia, N.; Truhlar, D. J Phys Chem A 2005, 109, 2012.

96. Sun, L. P.; Song, K. Y.; Hase, W. L. Science 2002, 296, 875.

97. Gonzales, J. M.; Pak, C.; Cox, R. S.; Allen, W. D.; Schaefer, H. F.; Csaszar, A. G.; Tarczay, G. Chem Eur J 2003, 9, 2173.

98. Gonzales, J. M.; Cox, R. S.; Brown, S. T.; Allen, W. D.; Schaefer, H. F. J Phys Chem A 2001, 105, 11327.
99. Lee, Y. S.; Worthington, S. E.; Krauss, M.; Brooks, B. R. J Phys Chem B 2002, 106, 12059.

100. Chook, Y. M.; Gray, J. V.; Ke, H. M.; Lipscomb, W. N. J Mol Biol 1994, 240, 476.

101. Lee, A. Y.; Stewart, J. D.; Clardy, J.; Ganem, B. Chem Biol 1995, 2 , 195.

102. Kast, P.; Asif-Ullah, M.; Hilvert, D. Tetrahedron Lett 1996, 37, 2691.

103. Ganem, B. Angew Chem Int Ed Engl 1996, 35, 937.

104. Galopin, C. C.; Zhang, S.; Wilson, D. B.; Ganem, B. Tetrahedron Lett 1996, 37, 8675 .

105. Haslam, E. Shikimic Acid: Metabolism and Metabolites; Wiley: New York, 1993

106. Andrews, P. R.; Smith, G. D.; Young, I. G. Biochemistry 1973, 12, 3492.

107. Ranaghan, K. E.; Ridder, L.; Szefczyk, B.; Sokalski, W. A.; Hermann, J. C.; Mulholland, A. J. Org Biomol Chem 2004, 2, 968.

108. Ranaghan, K. E.; Ridder, L.; Szefczyk, B.; Sokalski, W. A.; Hermann, J. C.; Mulholland, A. J. Mol Phys 2003, 101, 2695.

109. Szefczyk, B.; Mulholland, A. J.; Ranaghan, K. E.; Sokalski, W. A. J Am Chem Soc 2004, 126, 16148

110. Crespo, A.; Marti, M. A.; Estrin, D. A.; Roitberg, A. E. J Am Chem Soc 2005, 127, 6940 .

111. Hall, R. J.; Hindle, S. A.; Burton, N. A.; Hillier, I. H. J Comput Chem 2000, 21, 1433.

112. Krylov, A. I. Chem Phys Lett 2001, 338, 375.

113. Slipchenko, L. V.; Krylov, A. I. J Chem Phys 2002, 117, 4694.

114. Shao, Y. H.; Head-Gordon, M.; Krylov, A. I. J Chem Phys 2003, 118, 4807. 